\title{
Climatology of free-tropospheric humidity: extension into the SEVIRI era, evaluation and exemplary analysis
}

\author{
M. Schröder ${ }^{1}$, R. Roca ${ }^{2}$, L. Picon ${ }^{3}$, A. Kniffka ${ }^{1}$, and H. Brogniez ${ }^{4}$ \\ ${ }^{1}$ Satellite-Based Climate Monitoring, Deutscher Wetterdienst, Offenbach, Germany \\ ${ }^{2}$ OMP/LEGOS/CNRS, Toulouse, France \\ ${ }^{3}$ Sorbonne Universités, UPMC Univ. Paris 06; CNRS/INSU; ENS; Ecole Polytechnique; LMD-IPSL, UMR8539, \\ Paris, France \\ ${ }^{4}$ Université Versailles St-Quentin; Sorbonne Universités, UPMC Univ. Paris 06; CNRS/INSU, LATMOS-IPSL, \\ Guyancourt, France \\ Correspondence to: M. Schröder (marc.schröder@dwd.de)
}

Received: 7 March 2014 - Published in Atmos. Chem. Phys. Discuss.: 9 April 2014

Revised: 12 September 2014 - Accepted: 12 September 2014 - Published: 23 October 2014

\begin{abstract}
A new free-tropospheric humidity (FTH) data record is presented. It is based on observations from the Meteosat Visible and Infrared Imager (MVIRI) onboard Meteosat-2-Meteosat-5, as well as Meteosat-7, and the Spinning Enhanced Visible and Infrared Imager (SEVIRI) onboard Meteosat -8 and Meteosat- 9 at the water absorption band near $6.3 \mu \mathrm{m}$. The data set is available under clear-sky and low-level cloud conditions. With the extension to SEVIRI observations, the data record covers the period 19832009 with a spatial resolution of $0.625^{\circ} \times 0.625^{\circ}$ and a temporal resolution of $3 \mathrm{~h}$.

The FTH is the mean relative humidity $(\mathrm{RH})$ in a broad layer in the free troposphere. The relation between the observed brightness temperature (BT) and the FTH is well established. Previous retrievals are refined by taking into account the relative humidity Jacobians in the training process of the statistical retrieval. The temporal coverage is extended into the SEVIRI period, the homogenization of the BT record is improved, and the full archive is reprocessed using updated regression coefficients.

The FTH estimated from the Meteosat observations is compared to the FTH computed from the RH profiles of the Analyzed RadioSoundings Archive (ARSA). An average relative bias of $-3.2 \%$ and a relative root-mean-square difference (RMSD) of $16.8 \%$ are observed. This relative RMSD agrees with the outcome of an analysis of the total uncertainty of the FTH product. The decadal stability of the FTH data record is $0.5 \pm 0.45 \%$ per decade.
\end{abstract}

As exemplary applications, the interannual standard deviation, the differences on decadal scales, and the linear trend in the FTH data record and in the frequency of occurrence of FTH $<10 \%$ (FTHp10) are analyzed per season. Interannual standard deviation maxima and maxima in absolute decadal differences are featured in gradient areas between dry and wet regions, as well as in areas where FTH reaches minima and FTHp10 reaches maxima. An analysis of the FTH linear trends and of the associated uncertainty estimates is achieved to identify possible problems with the data record. Positive trends in FTHp10 are featured in gradient areas between wet and dry regions, in regions where the FTH is minimum, in regions where FTHp10 is maximum, and in regions where differences between FTHp10 averaged over the 2000s and 1990s are negative. However, these positive trends in FTHp10 are associated with maximum standard deviation and are thus hardly significant. This analysis and intercomparisons with other humidity data records are part of the Global Energy and Water Cycle Experiment (GEWEX) Water Vapor Assessment (G-VAP).

\section{Introduction}

The importance of relative humidity $(\mathrm{RH})$ in the free troposphere originates from the nonlinear interaction between $\mathrm{RH}$ and longwave radiation. In order to realistically assess the impact of RH in the free troposphere on longwave radiation, 
the full probability distribution of RH needs to be considered. However, the outgoing longwave radiation (OLR) is much more sensitive to perturbations at the dry end than at the moist end of the distribution (Spencer and Braswell, 1997; Roca et al., 2011). The magnitude of the differential impact of a given change at the dry end of the RH distribution compared to at the moist end of it can exceed a factor of 3 (Roca et al., 2011).

Most of the knowledge on the impact of climate change on $\mathrm{RH}$ in the free troposphere arises from theoretical and global average considerations (Pierrehumbert et al., 2007; Sherwood et al., 2010b; Shi and Bates, 2011; Roca et al., 2011, and references therein). On a global scale, the assumption of a constant upper-tropospheric RH under climate change conditions is supported by the work of Soden et al. (2002) and Soden and Held (2006), among others. However, the water vapor pressure is expected to be below equilibrium in most of the atmosphere. This is true in particular for the dry regions in the free troposphere. On the zonal mean scale, a common pattern emerges for a doubling of $\mathrm{CO}_{2}$ : subtropical dry regions shift poleward (Sherwood et al., 2010a), dry minima become drier (Hurley and Galewsky, 2010) and the width of these dry regions increases. Such impacts on the frequency of occurrence of the dry end of the FTH range (below $10 \%$, noted FTHp10 in the following) have been simulated with the Institut Pierre Simon Laplace climate model based on the analysis of the FTH distribution under a climate change scenario (Roca et al., 2011). On a regional scale, it is challenging to assess whether any of these large-scale features are reproduced and what is the expected change in their pattern if they are not reproduced. Sherwood et al. (2010a) reviewed the processes that determine the RH distribution in the intertropical region. A strong connection between large-scale dynamics and water vapor was found, and the role of eddies (e.g., mesoscale convection, circulation transients) in establishing these links highlighted the broad range of scales implied in the humidity distribution. The authors further indicated the need for the available theory to be better constrained.

These modifications of the spatial distribution of FTH correspond to the expected climate responses either at equilibrium after a $\mathrm{CO}_{2}$ doubling or at the end of the 21 st century. It is unclear how these modifications have been at play over the last 25-30 years and whether they can already be identified in the observational record of the last 25-30 years. Satellites observing the humidity in the free troposphere, and in particular geostationary platforms, appear to be very well suited to contribute to constraining the available theory by providing observations at kilometer- and hour-scale resolutions over a 30 -year-long period. One of the aims of the present paper is to provide a well-qualified data record to explore such possibility at the temporal and spatial scales of the Meteosat observations.

Infrared imagers and sounders whose channels are centered at the water vapor absorption band around $6.3 \mu \mathrm{m}$ as well as microwave sounders whose channels are centered at
183.31 GHz allow for the sounding of the free troposphere. Soden and Bretherton (1993) developed the commonly applied relationship between observed brightness temperature (BT) and free-tropospheric humidity (FTH) for infrared observations of cloud-free scenes. This proportionality is relative to a vertical average of the $\mathrm{RH}$ in the free troposphere and relies on the assumptions of random strong line theory and constant lapse rate. The regression coefficients depend on the averaging kernel and the performance of the regression can be improved by considering the so-called scaled reference pressure. Roca et al. (2003) statistically determined the regression coefficients and used reanalyses to determine the scaled reference pressure, whereas Schmetz et al. (1995) used reanalyses to determine regression coefficients on a pixel basis. Both retrievals were originally designed for Meteorological Satellite (Meteosat) Visible and Infrared Imager (MVIRI) observations. Buehler and John (2005) adapted the Soden and Bretherton (1996) method to intercalibrated Advanced Microwave Sounding Unit-B (AMSU-B) observations (John et al., 2013). The AMSUB-based FTH data record (Buehler et al., 2008) is affected by orbital drift, and it contains valid observations under allsky conditions except when intense scattering occurs, such as during precipitation events. The method described in Soden and Bretherton (1996) has recently been applied to three of the six channels of the Sondeur Atmosphérique du Profil d'Humidité Intertropicale par Radiometrie onboard the Megha-Tropiques satellite (Brogniez et al., 2014) launched in October 2011. Shi and Bates (2011) spent significant effort on recalibrating and intercalibrating the water vapor observations at $6.7 \mu \mathrm{m}$ of the High-resolution Infrared Radiation Sounder (HIRS). A subsequent application of the Soden and Bretherton (1996) method yields a FTH record that is longer than 30 years (Shi et al., 2013). The time series is affected by orbital drift, and, as is the case for the MVIRI observations, the FTH is retrieved under clear-sky and low-levelcloud conditions. Jackson and Bates (2001) assessed FTH algorithms that are applicable to HIRS observations at $6.7 \mu \mathrm{m}$. They concluded that the averaging kernel has a significant effect on the FTH retrieval and that the results are improved in the tropics when considering the scaled reference pressure in the retrieval (see Soden and Bretherton, 1996).

Brogniez et al. (2009) assessed the quality of the MVIRIbased FTH data record for the period 1984-2005. It is a precursor of the FTH data record presented here, and it was compared to FTH values which have been computed from RH profiles of a previous version of the Analyzed RadioSoundings Archive (ARSA). The mean difference between the MVIRI FTH and the ARSA FTH over the period 1984-2005 is $-1.2 \% \mathrm{RH}$, and the standard deviation of the difference is $1.7 \% \mathrm{RH}$, indicating the stability of the MVIRI archive over this period. The value of the FTH product has been demonstrated in, for example, Brogniez et al. (2005), who compared the FTH product against 14 climate models in the framework of the Atmospheric Model Intercomparison Project phase 2. 
Buehler and John (2005) estimated the theoretical uncertainty of the AMSU-B-based FTH retrieval scheme. They found a bias of $2 \% \mathrm{RH}$ for low values of FTH and $7 \% \mathrm{RH}$ for high values of FTH. John et al. (2011) further found a systematic clear-sky bias of $9 \%$ RH by sampling the allsky AMSU-B product with the HIRS clear-sky mask and by comparing the clear-sky and all-sky AMSU-B FTH products. An exemplary application of the AMSU-B FTH data record is given in Moradi et al. (2010). They found that the spatial distribution of radiosonde types coincides with the difference between AMSU-B data and data from the Integrated Global Radiosonde Archive (Durre et al., 2006). The HIRS data record has been evaluated in radiance space (see Shi and Bates, 2011) and the correlation of the BT with various climate indices has been analyzed (Shi et al., 2013), highlighting the valuable contribution of this data record to the analysis of global teleconnections.

The generation of FTH data records from Meteosat, AMSU-B and HIRS was part of a pilot project within the World Meteorological Organization's (WMO) Sustained, Coordinated Processing of Environmental Satellite Data for Climate Monitoring (SCOPE-CM) network, which aims to establish a network of facilities ensuring continuous and sustained provision of high-quality satellite products. Within new SCOPE-CM projects, the Meteosat, AMSU-B and HIRS data records will be homogenized in format, metadata and documentation as much as possible, and the observations from all available geostationary imagers will be recalibrated and intercalibrated. The impact of this Fundamental Climate Data Record (FCDR) on the Meteosat-based FTH product will also be evaluated within the SCOPE-CM projects.

The Global Energy and Water Cycle Experiment (GEWEX) Data and Assessments Panel has initiated the GEWEX Water Vapor Assessment (G-VAP). One element of G-VAP is the intercomparison of available long-term FTH data records and the analysis and the comparison of temporal changes in these data records. The present work supports the latter G-VAP activity by setting up the technical framework and by starting the analysis with the Meteosat-based FTH data record.

The objectives of this paper are (1) to describe the data and the algorithms used to produce the extended long-term stable FTH data record from the Meteosat observations, (2) to characterize the quality and the stability of this observational record by comparing it with independent data, and (3) to confront the variability of FTH on various temporal and spatial scales with the linear trends and their significance. The input data and the homogenization of Meteosat observations are introduced in Sects. 2 and 3, respectively. The retrieval scheme, an overview of the technical specifications, and exemplary figures on the characteristics of the FTH data record are presented in the next sections. The theoretically expected uncertainties are discussed in Sect. 5, and the evaluation results are shown in Sect. 6. The applications presented in Sect. 7 feature an analysis of the variability of the FTH and
FTHp10, of the FTHp10 differences on decadal scales, and of the linear trend in FTH and FTHp10. Finally, in Sect. 8, conclusions are drawn.

A series of statistical quantities and a list of abbreviations are given in the Appendices.

\section{Input data}

This section briefly describes the instruments and the radiance input data records used to retrieve the FTH.

MVIRI is a three-channel imaging radiometer onboard the Meteosat-2-7 platforms, which belong to the first generation of Meteosat satellites. It continuously observed the Earth from a geostationary orbit at $0^{\circ}$ latitude $/ 0^{\circ}$ longitude every $30 \mathrm{~min}$ between 1982 and 2006. The spatial sampling distance of the observations is approximately $5 \mathrm{~km}$ at nadir and it increases with distance from the sub-satellite point.

The Spinning Enhanced Visible and Infrared Imager (SEVIRI) performs observations at 12 channels that cover the visible and thermal infrared spectral range. SEVIRI is onboard the geostationary satellites Meteosat- $8-10$, which are positioned at $0^{\circ}$ latitude $/ 0^{\circ}$ longitude in operational mode. The SEVIRI full disc observations are repeated every $15 \mathrm{~min}$ between 2004 and the present day. The spatial sampling distance is $3 \mathrm{~km}$, increasing with distance from the sub-satellite point (Schmetz et al., 2002).

The elaboration of the Meteosat clear-sky radiance (CSR) archive is described in Brogniez et al. (2006), and it is briefly revisited in Sect. 3. The $6.3 \mu \mathrm{m}$ BTs, as observed by Meteosat-2 to Meteosat-5, as well as Meteosat-7, were taken from the International Satellite Cloud Climatology Project (ISCCP; Rossow and Schiffer, 1999) at the DX pixel resolution (ISCCP-DX; see http://isccp.giss.nasa.gov/products/ products.html for details). All observations are adapted to the Meteosat-5 spectral response function. The CSR archive built at the Laboratoire de Météorologie Dynamique (LMD, Paris, France) is used as input. It covers the period July 1983-June 2005. This CSR record has been extended using ISCCP-DX data for the period July 2005-June 2006. From July 2006 onwards, the SEVIRI observations are sampled to mimic the ISCCP-DX radiance data.

The FTH retrieval can reliably be applied under clear-sky and low-level-cloud (cloud-top pressure larger than $700 \mathrm{hPa}$ ) conditions. The sampling is largely improved when observations from the latter case are included. The scene selection is performed using the cloud information (e.g., cloud cover and cloud-top pressure) of ISCCP-DX for the period 1983-2009.

\section{Homogenization and extension to the SEVIRI era}

Prior to the FTH inversion, the CSR data record is adapted to the Meteosat-5 spectral response function. Scatterplots of simulated BTs from Meteosat-5 and Meteosat- 8 , as well as Meteosat-5 and Meteosat-9, exhibit an excellent linear 
behavior with correlations $>0.99$ (not shown). A linear equation with slope $a$ and with intercept $b$ is thus used for adaptation. The coefficients for Meteosat-5/Meteosat- 8 are $a=1.0160$ and $b=-2.3498$. The coefficients for Meteosat5/Meteosat-9 are $a=1.0174$ and $b=-2.6033$.

The Meteosat time series is not fully homogeneous and exhibits breakpoints in the BT time series, mainly due to satellite changes and changes in calibration. Such breakpoints can be removed using homogenization approaches. The homogenization applied here largely follows the work by Picon et al. (2003).

The basic approach is (1) to use the European Centre for Medium-Range Weather Forecasts (ECMWF) reanalyses ERA-Interim data (Dee et al., 2011) as input to the Radiative Transfer for the TIROS Operational Vertical Sounder (RTTOV) 9.3 model, (2) to simulate Meteosat-5 BT and (3) to apply a linear regression to the observed BT for a month prior to and after the breakpoint (adapted from Picon et al., 2003):

$$
\begin{aligned}
\mathrm{BT}_{\text {corrected }} & =\frac{a_{\text {before }}}{a_{\text {after }}} \mathrm{BT}_{\text {original }}+b_{\text {before }}-b_{\text {after }} \frac{a_{\text {before }}}{a_{\text {after }}}, \\
& =a^{\prime} \mathrm{BT}_{\text {original }}+b^{\prime} .
\end{aligned}
$$

Output from the regression is used to modify the satelliteobserved BT after the breakpoint in a way that preserves the bias and the root-mean-square difference (RMSD) between observed and simulated BT. The underlying assumption is the stability of ERA-Interim simulations over the 2-month period.

In order to perform the comparison, the following criteria have been applied:

- Only data at 06:00 and 12:00 UTC have been considered.

- Simulations are performed under clear-sky conditions only. This is further constrained by considering the warmest $80 \%$ in simulated radiances only.

- The subdomain covers $\pm 45^{\circ} \mathrm{N} / \mathrm{S}$ and $\pm 45^{\circ} \mathrm{E} / \mathrm{W}$.

The homogenization coefficients $a^{\prime}$ and $b^{\prime}$ can be computed after a double application of the linear regression and after substituting for the simulated BT.

This approach is applied to homogenize the change in calibration in January 2001 as well as the Meteosat-7/8 and Meteosat-8/9 transitions using ERA-Interim data for the months of December 2000 and January 2001, June and July 2006, and April and May 2007, respectively. The following parameters have been computed and applied:

- from January 2001 onwards: $a^{\prime}=0.98908$ and $b^{\prime}=$ 2.10135;

- from July 2006 onwards: $a^{\prime}=1.01510$ and $b^{\prime}=$ 1.00681

- from May 2007 onwards: $a^{\prime}=0.974119$ and $b^{\prime}=$ 5.31705 .

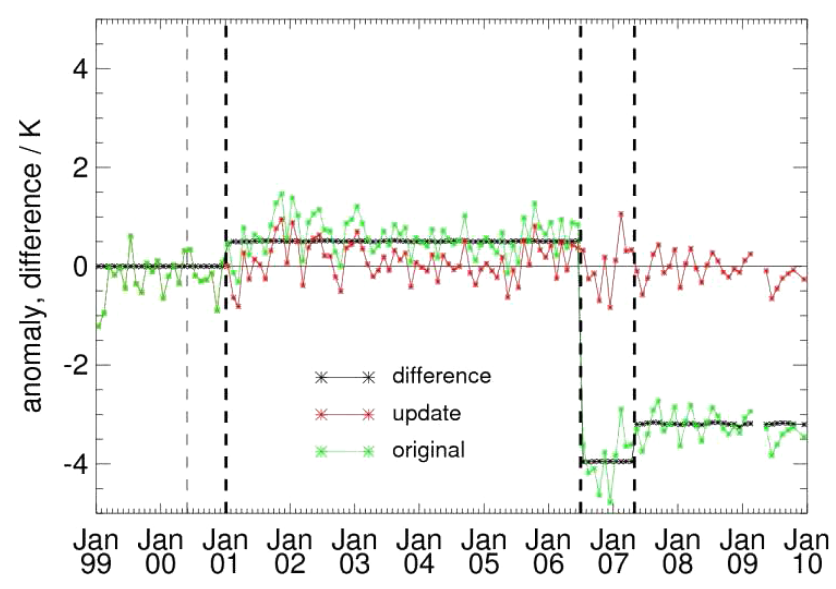

Figure 1. Monthly deseasonalized clear-sky brightness temperature anomaly for the original data (green) and for the updated homogenized data (red). The black line shows the difference between both anomalies. The thick dashed vertical lines represent the time when homogenization was applied and the thin dashed line represents the time when the blackbody calibration was implemented.

After homogenization, the intercalibration to HIRS (Breon et al., 2000) is applied to the CSR data. The results are consistent with HIRS channel-12 observations onboard the NOAA12 (National Oceanic and Atmospheric Administration satellite) and the known bias of Meteosat-5 is removed. These extended, homogenized and intercalibrated CSR data are used as input to the FTH retrieval described in the next section.

Figure 1 shows the deseasonalized anomaly of the original and the updated BT, as well as their difference. The intensity of a breakpoint is the difference between the anomaly difference (black values) prior and after the breakpoint. The breakpoints in January 2001, July 2006 and May 2007 have the following intensities: $0.5,-4.5$ and $0.8 \mathrm{~K}$, respectively. The degree of homogeneity and stability has been largely improved.

Results from the Global Space-based Inter-Calibration System over the period May 2008-December 2008 exhibit a difference in bias of slightly less than $0.5 \mathrm{~K}$ between Meteosat- 8 and Meteosat-9 relative to the Infrared Atmospheric Sounding Interferometer. The observing periods and the magnitude of the bias are different, but the result confirms the presence of a small bias between Meteosat- 8 and Meteosat- 9 in the early Meteosat- 9 phase. Note that this bias is significantly smaller in 2009 and later on.

As far as the first generation of Meteosat observations is concerned, the vicarious calibration has been replaced by the calibration using the onboard blackbody in May 2000, and an updated version has been implemented in January 2001 (http://www.eumetsat.int/website/home/ Data/Products/Calibration/MFGCalibration/index.html). In 

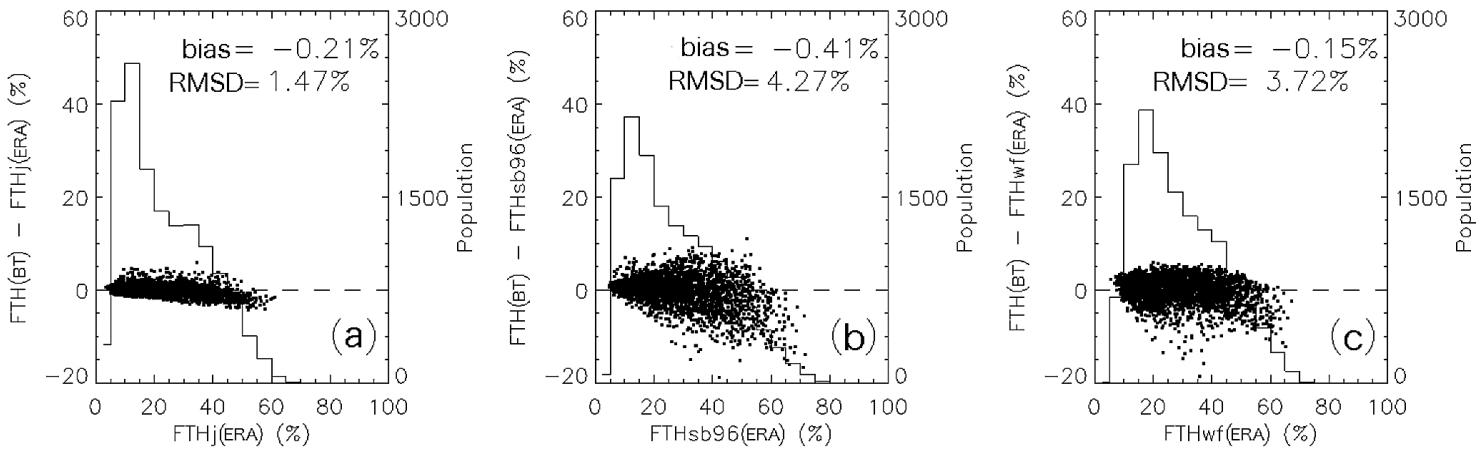

Figure 2. Scatterplot of the bias between "retrieved" FTH from simulated BT and "observed" FTH using the local Jacobian ("FTHj", left panel), the idealized Jacobian ("FTHsb96", middle panel) and the transmission-derived weighting function ("FTHw", right panel). Temperature and specific humidity from ERA-40 were used as input. The histogram gives the "observed" FTH population described on the right-hand side of the graphs. The average bias and the average RMSD are also given.

the time between, the eclipses that occurred in 2000 and in 2001 affected the overall performance (Köpken, 2001). Finally, several gain changes have been applied, in particular on 9 January 2001 (http://www.eumetsat.int/website/home/ Data/ServiceStatus/MeteosatGainSettings/index.html).

\section{The free-tropospheric relative humidity retrieval scheme}

\subsection{Rationale for the retrieval}

Assuming a random strong line theory and a constant lapse rate, Soden and Bretherton (1993) showed that the observed $\mathrm{BT}$ is proportional to the logarithm of the mean $\mathrm{RH}$ over a deep layer of the troposphere. Under these assumptions, the observed BT is mainly a function of RH alone and not of temperature and specific humidity separately. The FTH is determined from the following equation, which was analytically determined by Soden and Bretherton (1996):

$\ln \left(\frac{\langle\mathrm{RH}\rangle p_{\mathrm{o}}}{\cos (\theta)}\right)=a \times \mathrm{BT}_{6.3 \mu \mathrm{m}}+b$.

This equation links the clear-sky BT at $6.3 \mu \mathrm{m}$ to the mean RH (defined with respect to water only) of a broad layer of the troposphere. Eq. (2) also corrects for the effect of the satellite viewing angle, $\theta$, and it includes a scaling parameter, $p_{0}$, which is defined as the ratio between the pressure at a temperature of $240 \mathrm{~K}$ and $300 \mathrm{hPa}$. The parameter $p_{0}$ represents the deviation from a standard tropical profile where the $240 \mathrm{~K}$ isotherm is located at $300 \mathrm{hPa}$ (see Soden and Bretherton, 1993). In practice, this thermal parameter $p_{0}$ is computed using ERA-Interim and ERA-40 (Uppala et al., 2005) temperature profiles collocated with Meteosat observations. Level profiles from ERA-Interim (since January 2006) and ERA-40 (until December 2005) models are preferred over the standard pressure levels. Indeed, Roca et al. (2009) proved that the vertical resolution does not signifi- cantly affect the quality of the estimation of the FTH as long as a there is a given minimum number of pressure levels.

The fitting parameters $(a$ and $b)$ of the BT-to- $<\mathrm{RH}>$ retrieval are determined once using a representative data set of thermodynamic profiles and by sampling the satellite field of view. This training database is composed of temperature $(T)$ and specific humidity $(q)$ profiles extracted from ERAInterim restricted to clear-sky profiles. The database contains profiles from the first day (four time steps per day) of January, April, July and October for the years 2001, 2006 and 2007 in order to have a significantly large set of profiles sampling the various thermodynamical conditions encountered in the area limited to $30^{\circ} \mathrm{N} / \mathrm{S}$ covered by Meteosat. The clearsky cases are defined using the ERA-Interim cloud fraction with a strict value of 0 at all levels. In addition to the cloud screening, a quality check is performed for the RH profiles (determined with respect to the water phase only) to remove the dry and supersaturated cases where the $\mathrm{RH}$ reaches values below $1 \% \mathrm{RH}$ and above $100 \% \mathrm{RH}$ in the free troposphere.

\subsection{Definition of FTH and selection of the vertical averaging operator}

There are several definitions of the vertical averaging operator $\langle\cdot\rangle$ involved in the FTH retrieval according to the interpretation of the observed radiation (Brogniez et al., 2009):

- the idealized Jacobian $\Delta \mathrm{BT} / \Delta \mathrm{RH}$, for which the weights are defined in temperature coordinates (e.g., Soden and Bretherton, 1993; Soden and Bretherton, 1996);

- the local relative humidity Jacobian $J_{\mathrm{RH}}=\partial \mathrm{BT} / \partial \mathrm{RH}$ (e.g., Roca et al., 2003; Brogniez, 2004; Brogniez et al., 2004);

- the transmission-derived weighting function $\partial \tau / \partial \ln (p)$ (e.g., Schmetz and Turpeinen, 1988; Stephens et al., 1996). 

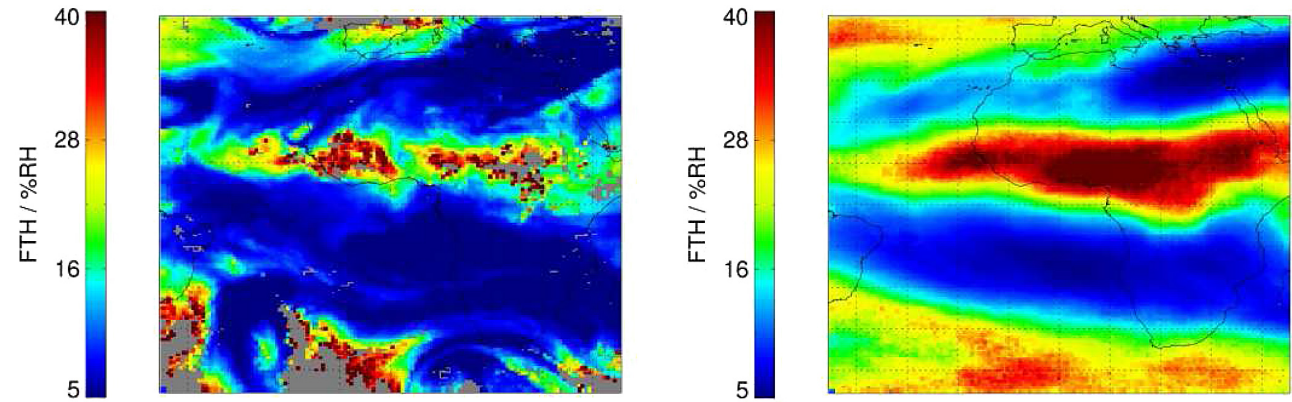

Figure 3. Instantaneous FTH at 12:00 UTC on 15 July 2009 (left panel) and monthly averaged FTH for July 2009 (right panel). Undefined areas are in grey and they are usually associated with cloud-top pressures above $700 \mathrm{hPa}$.

Jacobians and their usefulness in deriving atmospheric state parameters from satellite observations are described in, for example, Eyre (1987). The selection of the most appropriate averaging operator for the retrieval is based on a comparison between the three regressions defined from the three definitions of FTH and using ERA-40 data. Figure 2 illustrates the results of this evaluation with scatterplots of the bias between the weighted RH profiles ("observed") and the computed FTH using simulated BTs ("retrieved") and the "observed" FTH. The statistics provided in Fig. 2 clearly highlight the higher quality of the fit obtained with $J_{\mathrm{RH}}$, and thus the more precise definition of the FTH using $J_{\mathrm{RH}}$. Roca et al. (2009) analyzed the differences in spatial distribution of the peak height of the three different averaging operators. They showed that the spatial distribution of the peak heights resembles the spatial distribution of RH when using $J_{\mathrm{RH}}$ and the transmission-derived weighting function. The latter exhibits a bimodal distribution that is not featured in $J_{\mathrm{RH}}$ results.

The FTH is thus defined as the mean RH weighted by $J_{\mathrm{RH}}$ and normalized by the sum of weights. The layer between 150 and $700 \mathrm{hPa}$ is considered in the FTH computation:

$$
\mathrm{FTH}(\mathrm{RH})=\frac{\sum_{p=700 \mathrm{hPa}}^{150 \mathrm{hPa}} \mathrm{RH}(p) \times J_{\mathrm{RH}}(p)}{\sum_{p=700 \mathrm{hPa}}^{150 \mathrm{hPa}} J_{\mathrm{RH}}(p)},
$$

with $\mathrm{RH}(p)$ defined between 0 and $100 \%$ with respect to the liquid phase of water.

Using this definition, the training of the algorithm yields $a=-0.1248$ and $b=33.46$ (Roca et al. (2009).

\subsection{Practical considerations and examples}

The retrieval was applied to observations from Meteosat-2 to Meteosat-5 and from Meteosat-7 to Meteosat-9 and provides FTH values within $\pm 45^{\circ}$ longitude and $\pm 45^{\circ}$ latitude. The FTH is available at $3 \mathrm{~h}$ resolution and as monthly averages (arithmetic averages over all valid observations) on a regular latitude/longitude grid with a spatial resolution of $0.625^{\circ} \times 0.625^{\circ}$. The data record covers the period from July 1983 to December 2009. For the reasons given in Brogniez et al. (2009), the Meteosat-6 period (i.e., from March 1997 to May 1998) is not covered.

In the following, relative units of FTH are given in percent and the absolute units of FTH in percent RH.

Figure 3 shows examples of instantaneous and monthly averaged products. Figure 4 illustrates the FTH seasonal averages featuring strong FTH minima over northern and southern Africa during boreal summer and strong FTH maxima in the Intertropical Convergence Zone (ITCZ). The location and the extent of dry and wet areas and the corresponding minimum and maximum FTH values strongly depend on the season. Figure 5 shows the time series of FTH spatially averaged in the three regions shown in Fig. 4. The three time series exhibit large differences in amplitude and in shape of the annual cycle. Note that minor changes in the definition of the regions have a noticeable impact on the time series, in particular on outliers. Exemplary outliers are observed in March 1992 (in the South Atlantic) and in April 1990 (over northeastern Africa), and they seem to be caused by deviations from the climatological behavior of atmospheric dynamics on the regional scale.

As mentioned earlier, the identification of clear sky and low-level cloud in the Meteosat observations depends on ISCCP-DX data, and the quality of FTH depends on the quality of the cloud classification. A strong degradation of the FTH quality can be expected when high-level clouds are not correctly identified. Coastal areas exhibit reduced FTH data quality due to problems with cloud detection before February 1997. The retrieval is also not reliable over elevated terrain with surface pressures less than $700 \mathrm{hPa}$, since the observed signal might contain contributions from the surface.

The FTH data record is referenced under digital object identifier doi:10.5676/EUM_SAF_CM/FTH_METEOSAT/V001 and is freely available at http://www.cmsaf.eu/wui. 

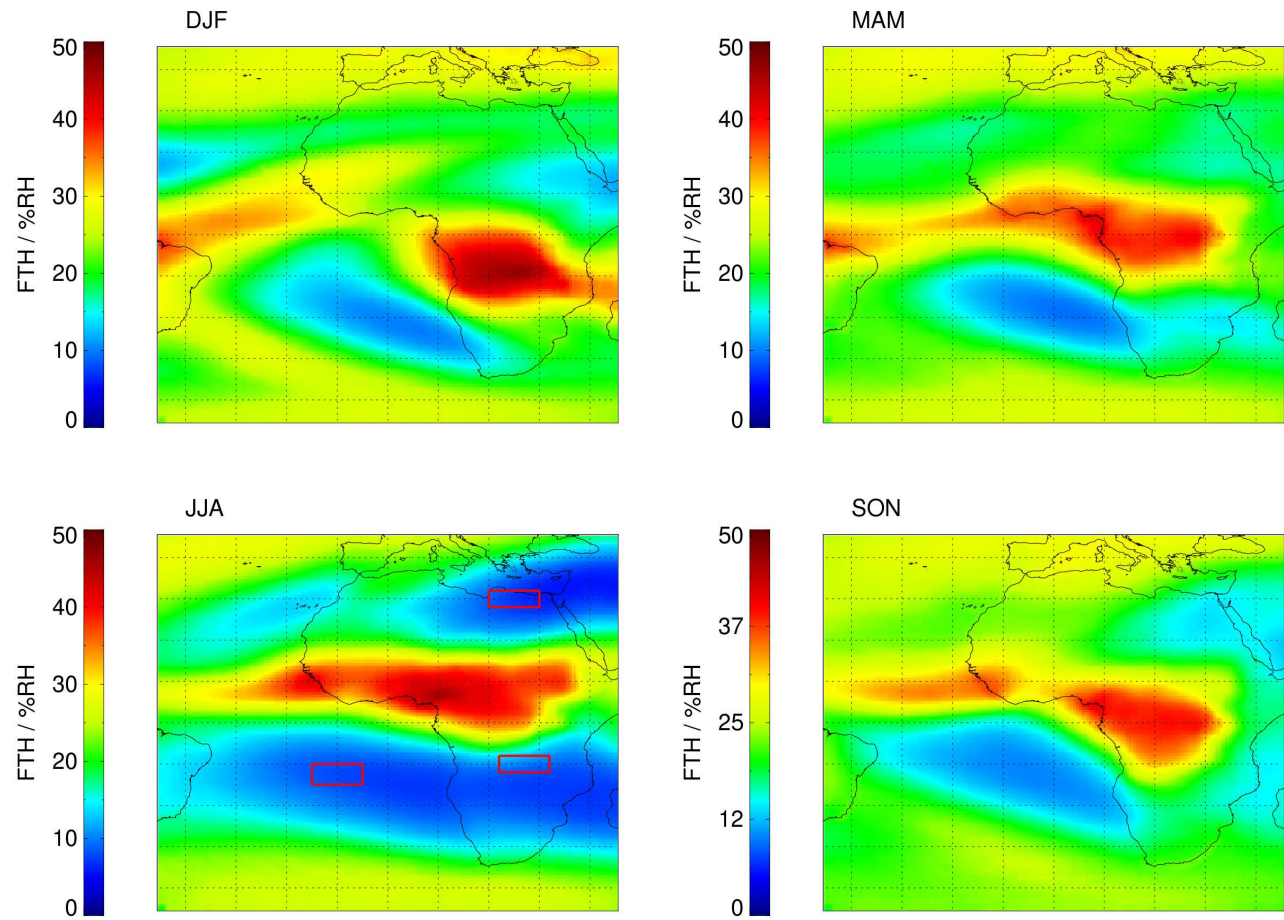

Figure 4. FTH seasonal averages: December-January-February (DJF, top left), March-April-May (MAM, top right), June-July-August (JJA, bottom left) and September-October-November (SON, bottom right). The period considered is 1984-2009. The red boxes indicate regions for which the average time series is plotted in Fig. 5.
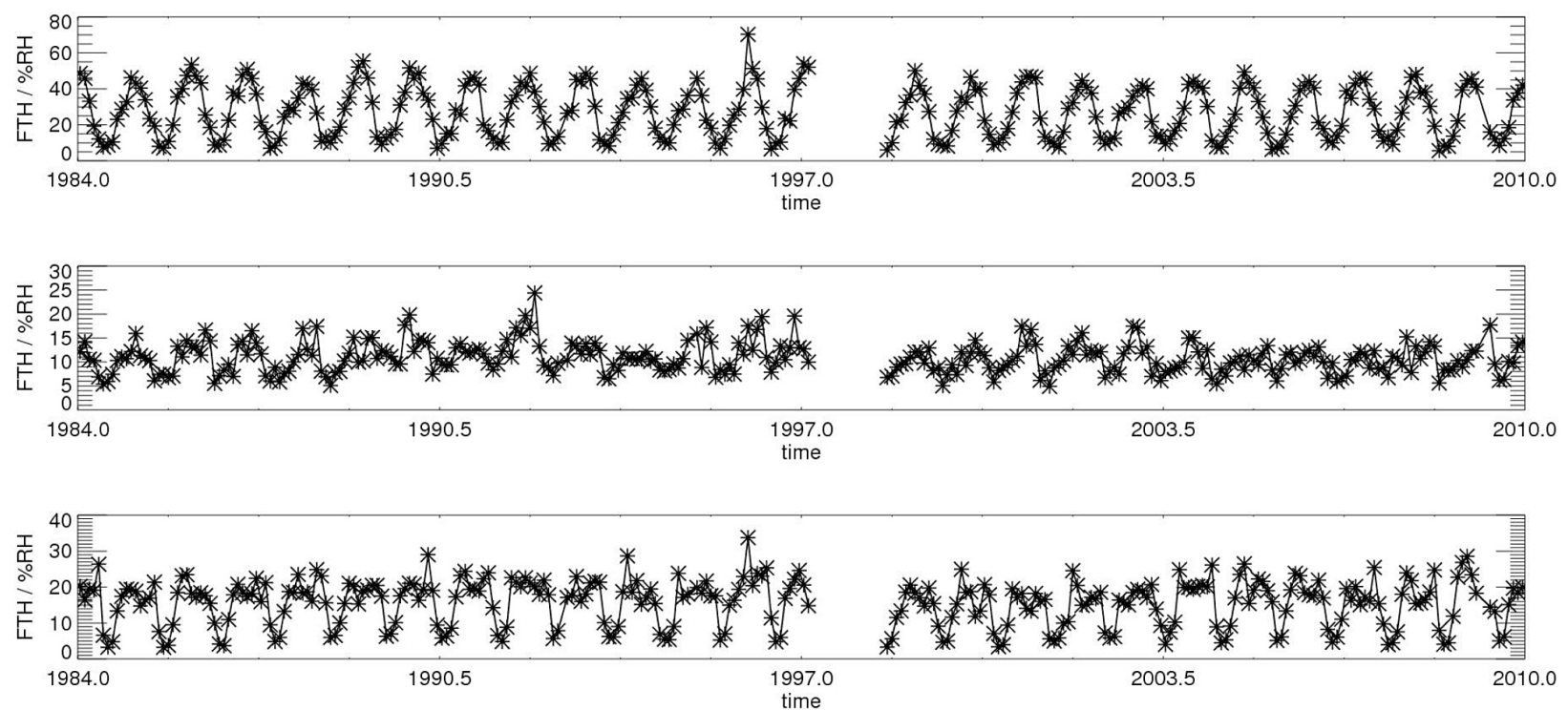

Figure 5. Time series of regional FTH averaged over south-central Africa (top), the South Atlantic (middle) and northeastern Africa (bottom). The regions are shown in the bottom left panel in Fig. 4.

\section{Towards an uncertainty budget estimate}

This section briefly discusses the uncertainty budget estimate for the FTH product. Following Chambon et al. (2012), the uncertainty budget is composed of three main uncertainty source terms: (1) calibration uncertainty, (2) retrieval uncertainty and (3) sampling uncertainty. In line with Roca et al. (2010) the calibration uncertainty is considered to be a systematic difference, whereas the retrieval uncertainty depends on the details of the underlying algorithm. The 
representativeness uncertainty depends on the temporal and spatial averaging, and it vanishes at the instantaneous pixel scale. This uncertainty depends on the number of independent observations. In order to estimate this number, the correlation length in space and time for the FTH has been estimated by analyzing variograms (see Roca et al., 2012, for details). Typical spatial correlation lengths of $350 \mathrm{~km}$ and temporal correlation lengths of $7.5 \mathrm{~h}$ have been observed.

An upper-bound calibration uncertainty of $1 \mathrm{~K}$ is considered (van de Berg et al., 1995). In this case, the relative uncertainty on FTH is equivalent to the intercept of the retrieval ( $b$ in Eq. 2) and is between 10 and 15\% (Roca et al., 2009). Results from the training of the FTH retrieval allow for the estimation of the retrieval uncertainty. Based on the tropical training, a RMSD of $2 \% \mathrm{RH}$ ( $8 \%$ when assuming an average FTH of $25 \%$ ) and an average difference of $0.3 \% \mathrm{RH}$ were estimated. Assuming a daily average over a $2.5^{\circ}$ grid box and a typical standard deviation of $20 \%$ yields a $10 \%$ relative sampling uncertainty. As a result, in this idealized case, the total uncertainty in the estimation of the mean FTH is equally driven by the calibration and the sampling terms, and to a lesser extent by the algorithm term. The estimated total uncertainty is the square root of the sum of the three variances, and in this case it is around 16-19\%, with a coverage probability of $68 \%$ (Roca et al., 2012).

\section{Evaluation}

\subsection{Data record for evaluation}

ARSA version 2.7 is an archive of global radiosonde measurements of temperature, water vapor and ozone profiles which have been quality controlled and combined with auxiliary observations. The ARSA archive has been developed and provided by the Atmospheric Radiation Analysis group at the LMD. In the first processing step, the radiosonde observations are quality controlled. For example, water vapor observations are considered only when they are available up to a minimum pressure of $350 \mathrm{hPa}$, and the Thermodynamic Initial Guess Retrieval (also developed at the LMD) climatological database is used to remove outliers. In the second step, existing radiosonde measurements are combined with other reliable data sources. This step depends on ERAInterim data, which are also used for extrapolation into upper levels of the atmosphere. Finally, the profiles are interpolated to 43 pressure levels from sea level pressure to $0.0025 \mathrm{hPa}$. ARSA covers the period between 1979 and 2013 with a few tens of thousands of observations per month. More details can be found at http://ara.abct.lmd.polytechnique.fr/index. php?page $=$ arsa.

\subsection{Methodology}

The evaluation approach using ARSA follows the approach given in Brogniez et al. (2006, 2009). In order to simulate the Meteosat-5 observations, the RTTOV9.3 model (Matricardi et al., 2004) has been applied to the ARSA profiles. The RTTOV model uses fast transmittance algorithms based on accurate transmittances obtained from line-by-line computations (GENLN2 for the 3-20 $\mu \mathrm{m}$ spectral range; Edwards, 1992). RTTOV uses HITRAN-2000 (Rothman et al., 2003) as spectroscopic data base. For the specific case of the $6.3 \mu \mathrm{m}$ strong vibration-rotation absorption band by water vapor, the RTTOV model takes into account the water vapor continuum (foreign-broadening and self-broadening, model CKD-2.4; Clough et al., 1989) that has a non-negligible contribution in the water vapor band (e.g., Stephens et al., 1996, and Soden et al., 2000). Based on the work of Brunel and Turner (2003) referenced in the RTTOV v9 user guide, the bias uncertainty of RTTOV with respect to the Meteosat water vapor channel is $<0.1 \mathrm{~K}$, with a standard deviation of $>0.3 \mathrm{~K}$.

RTTOV also includes the K-matrix model that computes standard Jacobians (among them $\partial \mathrm{BT} / \partial q$, where $q$ is the volume mixing ratio). $\partial \mathrm{BT} / \partial q$ is converted to $J_{\mathrm{RH}}$ by computing $e_{\mathrm{s}} \partial \mathrm{BT} / \partial q$, where $e_{\mathrm{s}}$ is the saturation vapor pressure. $J_{\mathrm{RH}}$ is used to integrate the ARSA observations. Note that the results of Chen et al. (2010), who assessed three different transmittance models through their impact on simulated radiances and Jacobians, can be interpreted as follows: RTTOV can benefit from improvements to the transmittance model for the computation of Jacobians in cold and dry atmospheric conditions.

The following selection criteria are applied for the validation:

- nighttime only,

- FTH $>5 \%$ to reduce potential surface contributions,

- absolute differences in BTs < $3 \mathrm{~K}$ (i.e., approximately $3 \sigma$ ) and simulated and observed BTs $>220 \mathrm{~K}$ to minimize cloud detection uncertainties of the ISCCP-DX algorithm.

A pair of ARSA and Meteosat observations is considered to be collocated when the temporal distance is within $1.5 \mathrm{~h}$ and the spatial distance is within $0.625^{\circ}$. Although ARSA contains measurements from radiosondes launched on ships and at small islands, the validation is dominated by observations over land.

To evaluate the quality of the FTH data record, the relative and absolute bias, the corresponding RMSD, and the decadal stability are determined on a monthly basis and as spatial averages. These uncertainty parameters are only considered when the number of valid observations is larger than 10. More detail is given in Appendix A.

\subsection{Results}

The time series of monthly averages of absolute and relative biases of the FTH from Meteosat and the FTH from ARSA, their absolute and relative RMSD, and the number of valid 


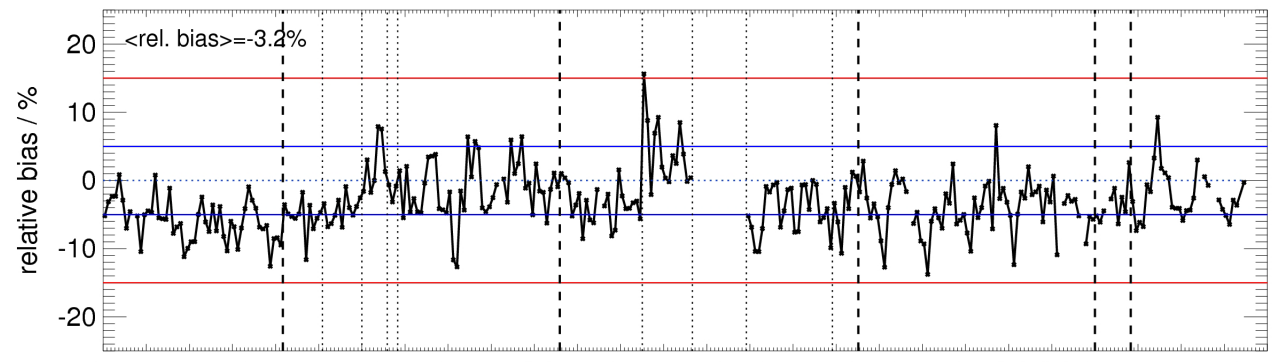

Jul Jul Jul Jul Jul Jul Jul Jul Jul Jul Jul Jul Jul Jul Jul Jul Jul Jul Jul Jul Jul Jul Jul Jul Jul Jul Jul Jul 83848586878889909192939495969798990001020304050607080910
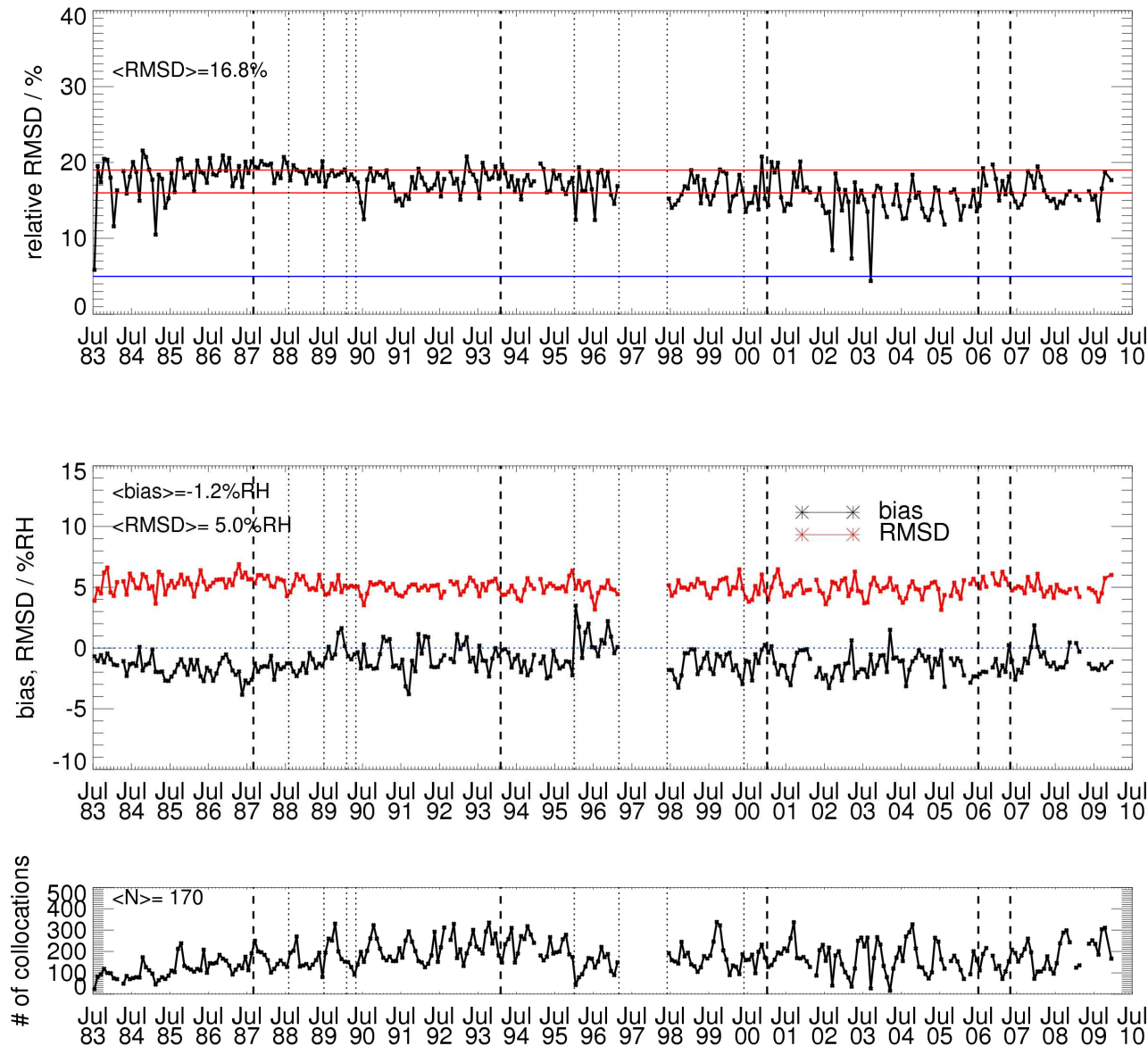

Figure 6. Monthly mean of the relative bias between the FTH from Meteosat and the FTH from ARSA (top panel), monthly mean of the relative RMSD between the Meteosat-FTH and the ARSA-FTH (second panel), monthly mean of the absolute bias between the MeteosatFTH and the ARSA-FTH, monthly mean of the RMSD (third panel) and number of valid observations ( $N$, bottom panel). The thick dashed and the thin dotted vertical lines indicate homogenization and major radiometric events. The averaged bias, the averaged RMSD and the averaged $N$ are also given. The colored lines in the first two panels highlight the FTH requirements from Global Climate Observing System (GCOS-154); the error budget estimate from Sect. 5; and a line at $15 \%$, which is close to the peak values in maximum relative bias.

observations $(N)$ are shown in Fig. 6. Over the period July 1983 to December 2009, the averaged relative bias, the averaged relative RMSD and the averaged $N$ are $-3.2,16.8$ and $170 \%$, respectively. The averaged relative bias and $55 \%$ of the monthly relative biases between the FTH from Meteosat and the FTH from ARSA are smaller than the Global Climate Observing System (GCOS) requirement for the FTH (5\%, as in GCOS-154). The relative bias between the FTH from Meteosat and the FTH from ARSA exhibits strong temporal fluctuations as well as a standard deviation of $4.5 \%$. N 
strongly fluctuates in time, and neither small nor large values of $N$ systematically coincide with maxima or minima in relative bias. No correlation is found $(R=-0.01)$ between $N$ and the relative bias (see Eq. (A3) for a definition of the Pearson correlation coefficient, $R$ ). Besides several local maxima and minima in the time series of the relative bias between the FTH from Meteosat and the FTH from ARSA, the following features are noteworthy:

- an increase in relative bias between the summers 1988 and 1990;

- a maximum in relative bias in January 1996, with spurious biases in 1996 .

These features most likely originate from changes in calibration procedures or instrumentation as discussed in Sect. 3. The main difference between the comparisons performed in the FTH space and in the BT space is that the features mentioned above appear to be enhanced in the relative bias of FTH due to the exponential relation between CSR and FTH and due to the normalization. Sharp summer minima in the relative bias with values down to almost $-15 \%$ are often featured. These minima are less obvious before 2001, and they are most likely caused by the increased uncertainty in the FTH retrieval when the troposphere is very dry. The relative RMSD between the FTH from Meteosat and the FTH from ARSA exhibits weaker variations than the relative bias and a slight decrease between 1988 and 2006. More than 66\% of the monthly relative RMSD values are within 16-19\%, which is the estimated uncertainty of the FTH product.

The features mentioned above are also highlighted on the time series of the absolute bias and RMSD (Fig. 6, third panel), but they appear to be damped. The most obvious difference is the lack of decrease in RMSD. The averaged bias and RMSD are stable and small over the period 1983-2009 ( $-1.2 \% \mathrm{RH}$ and $5.0 \% \mathrm{RH}$, respectively). The normalization step with respect to the FTH likely causes the decrease in relative RMSD, which is an indication of a general increase in FTH. Note that the normalization is done with respect to the FTH from ARSA. Finally, the annual cycle of the absolute bias between the FTH from Meteosat and the FTH from ARSA is less pronounced than the one of the relative bias because the normalization has an amplifying effect (e.g., the months of July and August exhibit the strongest minima and are characterized by larger dry regions than during the other months of the year).

Scatterplots and histograms of the difference between the FTH from Meteosat and the FTH from ARSA have been performed (not shown). A small bias between both FTH data records is noteworthy, with larger ARSA-based FTH values than Meteosat-based FTH values. The histogram of the differences peaks at $-1 \pm 1 \% \mathrm{RH}$ and is slightly skewed towards negative values.

The stability of the data record is considered to be the slope of the linear regression between the difference of the Meteosat FTH and the corresponding ARSA FTH (see Appendix A). Based on the differences shown in Fig. 6 (top panel) and after conversion from percent per month into percent per decade, the decadal stability is found to be $0.5 \pm 0.45 \%$, which envelops the GCOS requirement of $0.3 \%$ (GCOS-154). The uncertainty of the decadal stability is relatively large and is obvious in Fig. 6.

\section{$7 \quad$ Variability and trend analysis}

After introducing the frequency of occurrence of FTH $<10 \%$ (FTHp10), an analysis of the standard deviation of FTH and FTHp10 on interannual scale is performed and the correlation to the El Niño 3.4 and to the quasi-biennial oscillation (QBO) indices is presented as well as the differences between FTHp10 averaged over the 2000s and over the 1990s. This analysis contributes to the discussion of linear trends and associated uncertainties in Sect. 7.3. Intra-seasonal variability also contributes to the uncertainty, but it is not considered here.

Throughout this section, full years are considered from January 1984 to December 2009.

\subsection{FTHp10}

Roca et al. (2011) introduced the frequency of occurrence of dry air as a marker of the behavior of the dry part of the FTH distribution, namely the frequency of occurrence of FTHp10. This climatological indicator corresponds to the radiatively sensitive range of FTH and it is more resilient to the various assumptions in the retrieval (e.g., cloud clearing). A strong contrast between minima and maxima reveals the spatial distribution of the moisture field as seen in the FTHp10 seasonal climatology shown in Fig. 7. The locations of frequently dry areas coincide with locations of the dry seasonal averages in Fig. 4. Figure 7 further highlights the dry area in the southern tropical Atlantic Ocean where the air is very dry more than $70 \%$ of the time, and it highlights the strong FTHp10 maxima in amplitude and in spatial extent that occurs mostly during the boreal summer. The maximum FTHp10 is found in the northeastern Mediterranean Sea in the boreal summer climatology.

\subsection{Variability}

An analysis of the FTH and the FTHp10 temporal and spatial variability is of general interest, as outlined in the Introduction. In addition, the significance of FTH and FTHp10 trends is assessed in the next section. In general, the coverage probability (or level of confidence) is a function of the standard deviation and thus of the temporal variability. Therefore, the spatial distribution of the standard deviation is analyzed on the interannual scale, the correlation to El Niño 3.4 and QBO indices is discussed, and the differences between 

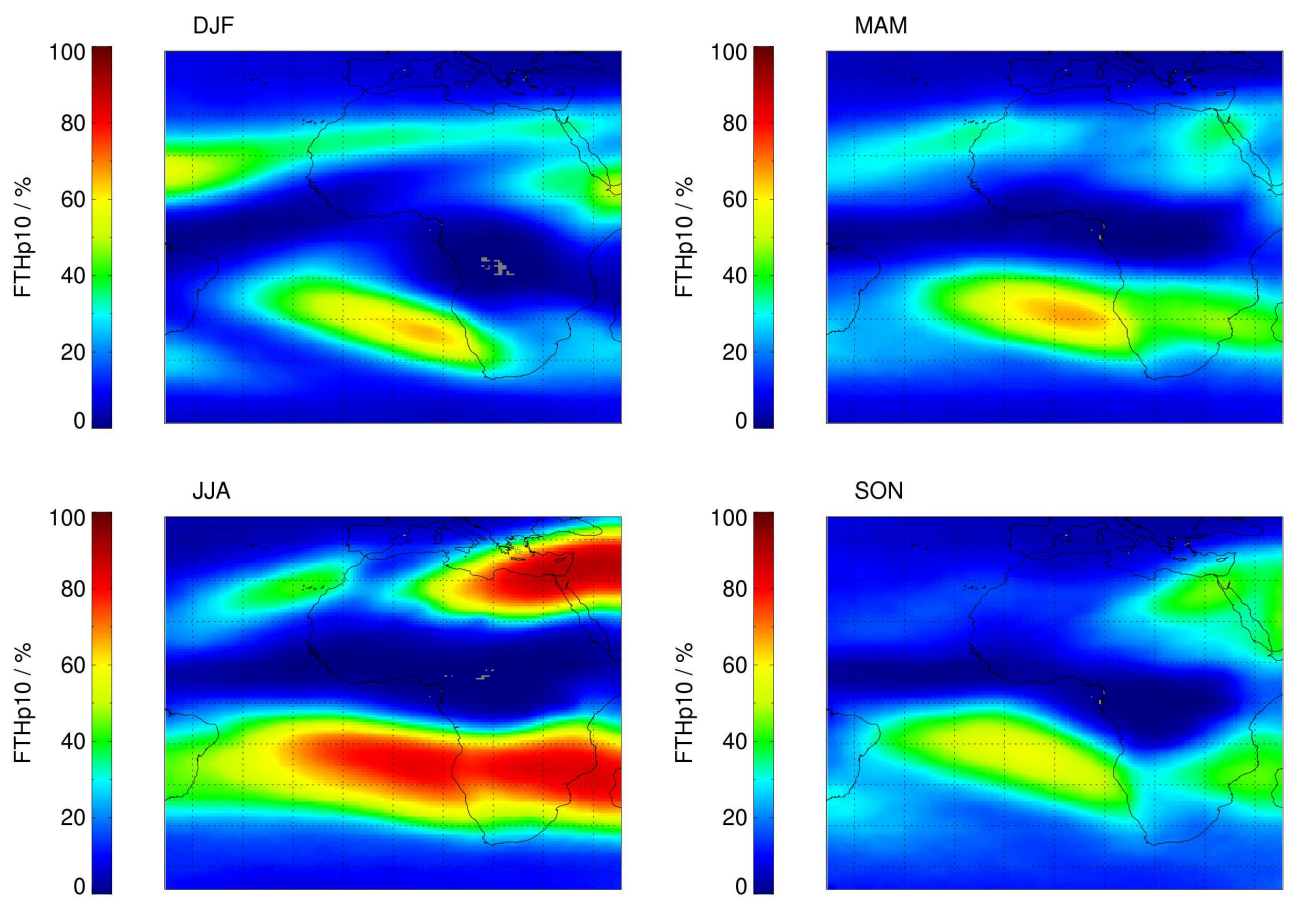

Figure 7. Same as Fig. 4 but for the frequency of occurrence of FTH < $10 \%$ (FTHp10). Areas where only a small number of observations are valid are shown in grey.

FTHp10 averaged over the 2000s and over the 1990s are analyzed.

In order to assess the interannual variability of FTH and FTHp10, Fig. 8 shows the relative standard deviation in FTH and in FTHp10 for each season. The relative standard deviation maxima in FTH are located over the South Atlantic, the North Atlantic and central-eastern Africa in DJF and over northeastern Africa in JJA. Minima are associated with the ITCZ and the extratropics. Note that the SON season clearly features the minimum averaged relative standard deviation, mainly due to largely reduced maxima during this season. The positions of maxima and minima in relative FTH standard deviation obviously coincide with the positions of the FTH minima and maxima but also with gradient areas between dry and wet regions. These results are in good agreement with the findings of Brogniez et al. (2009), and we recall here the outstanding relevance of the variability in the dry free troposphere on the outgoing longwave radiation (e.g., Udelhofen and Hartman, 1995; Sohn and Schmetz, 2004). Keeping in mind that FTH minima are associated with FTHp10 maxima, similar results are found for FTHp10, but only for the dry end of the distribution. Also, the strong maximum in relative standard deviation of FTH featured in the region of northeastern Africa in JJA appears as a local minimum in standard deviation of FTHp10, indicating a strong stability of the occurrence of dry events in this region.

Following Roca et al. (2011) large-scale dynamics have a strong impact on the FTH distribution and its variabil- ity. Brogniez et al. (2009) analyzed the FTH from MVIRI over northeastern Africa over the period 1983-2004 for the months of July/August and separated the analysis into dry and wet years. The air masses of the driest years have been shown to mainly originate from the tropics with a contribution from the extratropics, whereas the wet air masses originate from tropical regions only. The variability of the extent of specific features in FTHp10 over northeastern Africa in JJA and their position must also be analyzed to better understand the overall dynamics and underlying distributions of FTH, their impact on OLR and their changes over time.

The correlation coefficient $R$ between seasonal averages of FTH, FTHp10 and the El Niño 3.4 index (available at http: //www.esrl.noaa.gov/psd/data/climateindices/list/) has been analyzed (not shown). Only DJF averages have been considered because El Niño events are more intense during boreal winter. The coverage probability of the correlation has been computed as described in Shi et al. (2013). The averaged correlation coefficient for positive values only and for negative values only was found to be 0.14 and -0.11 , respectively. The number of grid cells with coverage probability of $95 \%$ or larger, relative to the total number of grid cells (in the following referred to as "area fraction") is $1.8 \%$ for FTH and $3.6 \%$ for FTHp10. The FTH and FTHp10 exhibit significant correlations over northeastern Africa and over parts of the Arabian Peninsula, with FTH (FTHp10) values being positively (negatively) correlated with the El Niño 3.4 index $(0.48 ;-0.45)$. The positive correlation for FTH is consistent 

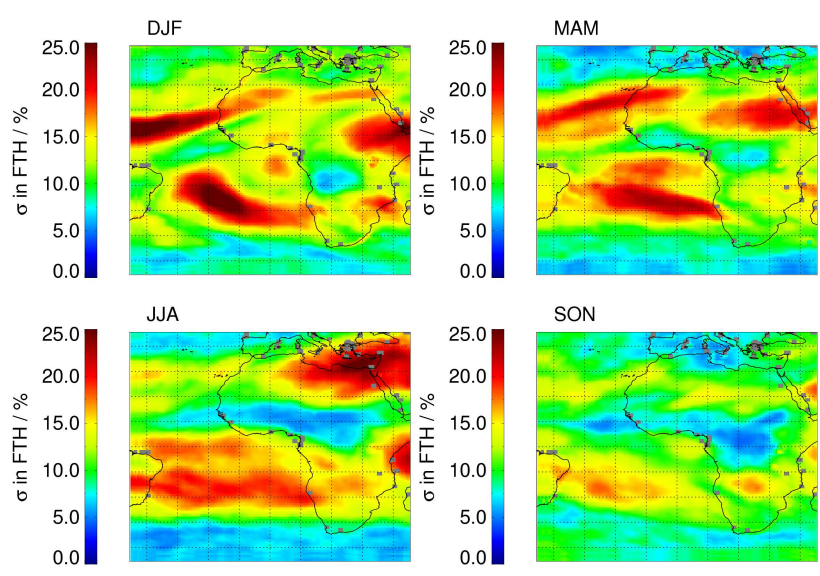

SON

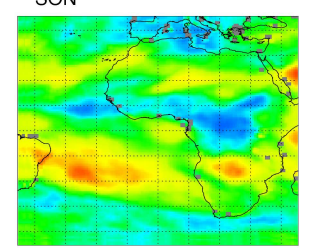

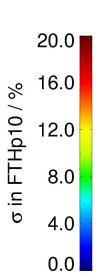
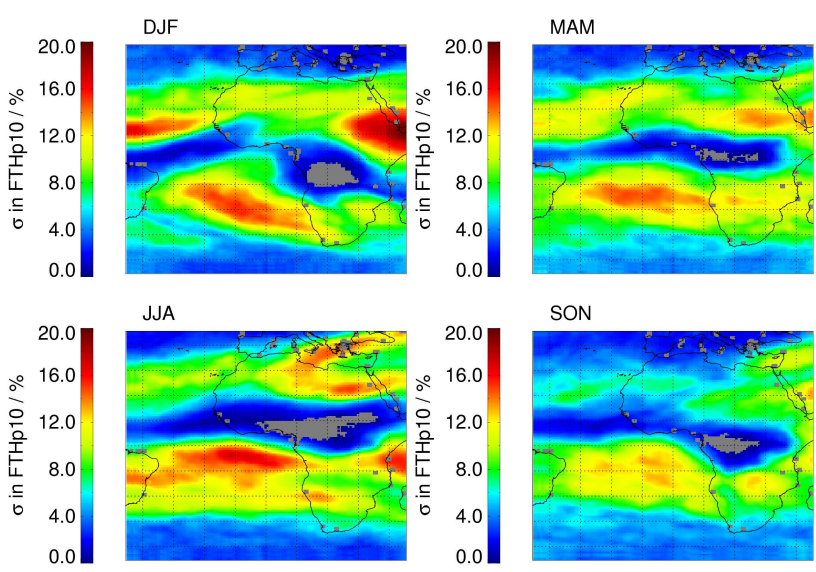

SON

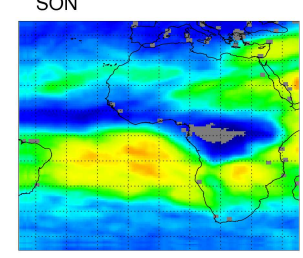

Figure 8. Relative standard deviation in FTH for each season (top four panels) and in FTHp10 (bottom four panels) over the period 1984-2009. Areas where only a small number of observations are valid are shown in grey.

with results of Shi et al. (2013), who analyzed the correlation between BT based on HIRS observations and the El Niño 3.4 index. Similarly, the correlation between deseasonalized FTH and FTHp10 values and the QBO index was analyzed. The total area fraction of significant correlation is slightly larger than for the correlation with the El Niño 3.4 index, but it is associated with averaged correlations about only 0.13 . El Niño events and the QBO thus have a minor contribution to the overall variability in FTH and FTHp10 over the considered area.

The FTH data record covers two full decades, namely the 1990s and the 2000s. The differences between FTHp10 averaged over the 2000s and over the 1990s are shown per season in Fig. 9. Negative values occur when FTHp10 values in the 2000s are larger than in the 1990s. Thus, FTHp10 is generally larger in the 2000s than in 1990s. The maximum area fraction of negative difference is $90 \%$ in DJF and the minimum area fraction of negative difference is $71 \%$ in SON. The regions of minimum difference mainly coincide with gradient areas between dry and wet regions and, to a smaller extent, with the dry regions themselves. The largest connected

area of positive difference is found over northeastern Africa in SON and is located at the west-southwest border of a regional FTHp10 maximum. This most likely corresponds to an east-northeast retreat of the dry region between the 1990s and 2000s. These differences were compared to the noise that is, to the square root of the squared sum of the internal decadal standard deviations (not shown). The maximum area fraction with an absolute ratio between the differences and the noise that is larger than 1 is $9 \%$ in DJF. The minimum area fraction with an absolute ratio between the differences and the noise that is larger than 1 is $1 \%$ in SON. Areas of large absolute ratios are typically found between the ITCZ and the neighboring dry areas. Even though most of the full area of interest exhibits an increase in the frequency of dry events, it cannot be concluded that this tendency is significant.

\subsection{Linear trend analysis}

\subsubsection{Methodology}

Two methods to analyze linear trends are tested: the "median of pair-wise slopes regression" method (referred to as the "Theil-Sen slope estimator"; Theil, 1950) and the linear regression method. The "Theil-Sen slope estimator" method is more robust (i.e., less sensitive to outliers) than linear regression and better suited to analyze linear trends in climatological data series. This estimator takes into account the median of all pair-wise slopes in the data. Approximately 600 pairs are needed to accurately estimate coverage probabilities (Wilcox, 2001), but the FTH data record only has 312. A simple linear regression computation has thus also been performed. Minor differences in absolute values and patterns of the different trends are observed (not shown). The linear regression method is thus used in the following. The estimated uncertainty of the trend is computed as described in Wilks (2011). Here, the autocorrelation is neglected because seasonal averages are considered. Based on the estimated uncertainty the coverage probability is estimated from a two-sided Student's $t$ test.

To increase the accuracy of the trend analysis, $5^{\circ} \times 5$ averages are used instead of the full resolution of the original product.

\subsubsection{Results}

Figures 10 and 12 show the linear trend in FTH and in FTHp10 as well as the associated coverage probabilities per season over the period 1984-2009. Positive (negative) trends in FTH largely coincide with negative (positive) trends in FTHp10, except over southeastern Europe in DJF, where FTHp10 exhibits trends that are around $0 \% \mathrm{yr}^{-1}$. Note that FTHp10 only reflects the very dry events, whereas the FTH has been averaged over the full range of FTH values. 

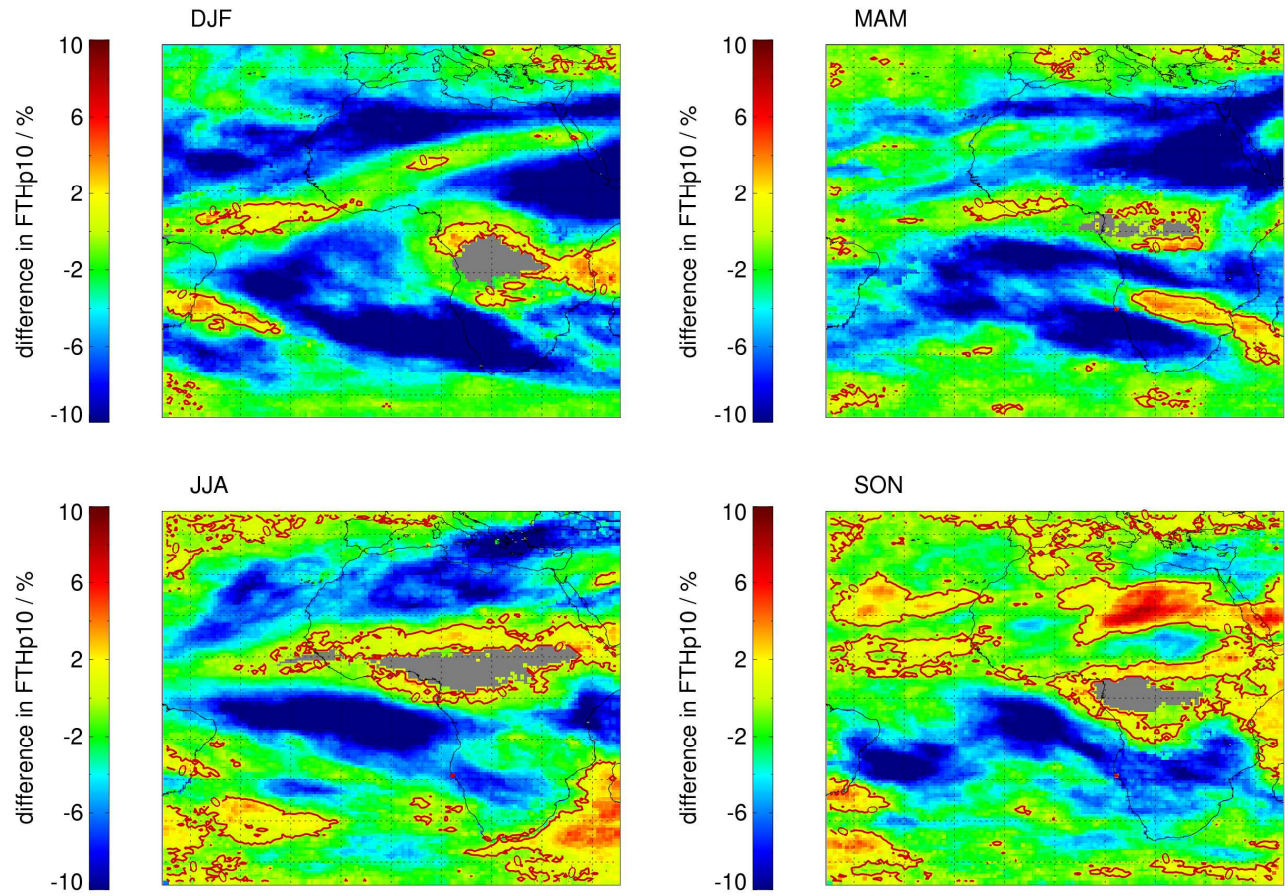

Figure 9. Difference between decadal averages of FTHp10 in the period 1990-1999 and in the period 2000-2009. The difference was computed per season. Red contour lines indicate a $0 \%$ difference. Areas where only a small number of observations are valid are shown in grey.

In general and for both FTH and FTHp10, the strongest trends are observed in areas where there is a strong gradient between dry and wet regions and in dry areas. The dipole structure of positive and negative trends in FTH and in FTHp10 over northeastern Africa in DJF and JJA is located at the borders of the associated dry regions. This can be an indication of a displacement of (frequently) dry events in these areas. The observed trends in FTH and in FTHp10 are hardly significant at the $95 \%$ confidence level. The minimum area fraction with significant trends at this confidence level is $2.5 \%$ (in $\mathrm{SON}$ ) and the maximum area fraction is $19.8 \%$ (in MAM), both found for FTHp10. The largest connected areas of significant trends are found in the extratropics. They coincide with generally large (small) values of FTH (FTHp10) and small estimated uncertainties. They should be interpreted with care because they are affected by potential oversimplifications of the retrieval scheme, which might occur in the extratropical environment, where the assumption of a constant lapse rate is no longer valid. The estimated uncertainties are shown in Figs. 11 and 13 for the FTH and FTHp10, respectively. Areas of large absolute trends frequently coincide with large estimated uncertainties but also appear slightly shifted compared to the estimated uncertainty maxima. An exception is the area of negative FTH trends, which is located over Brazil and the neighboring South Atlantic in SON. Strong similarities between the estimated uncertainty and the interannual variability arise from comparing Figs. 11 and 13 with
Fig. 8. The interannual variability thus dominates the estimated uncertainty. Together with the length of the record (26 years), this explains that significant trends in FTH and FTHp10 are hardly observed in this analysis.

Brogniez et al. (2009) reported that 1985 was among the driest years of the full FTH data record. Since this specific year is at the beginning of the time series, it strongly impacts the trend estimate. This impact has been assessed for FTHp10 by removing the first 2 years from the data record (not shown). After recomputing the trends, dry areas and gradient areas between dry and wet areas exhibit larger positive trends and connected areas of such trends cover larger areas. In particular, the dry area over northeastern Africa in JJA and the dry area over the South Atlantic in DJF exhibit significant positive trends at the $95 \%$ confidence level. Interestingly, the areas of significant trends in the extratropics in MAM and over central Africa in DJF almost disappear, which is associated with trends being close to zero. As stated in Santer et al. (2011), these results confirm that trend estimates, their significance and their uncertainty depend on the period considered and in particular on the statistics of the data at the start and end of the period.

Even though the estimated trends and the differences between FTHp10 averaged over the 2000s and over the 1990s are practically not significant and cover different periods, the spatial patterns of increasing FTHp10 values generally coincide with negative differences. Further analysis is needed to 

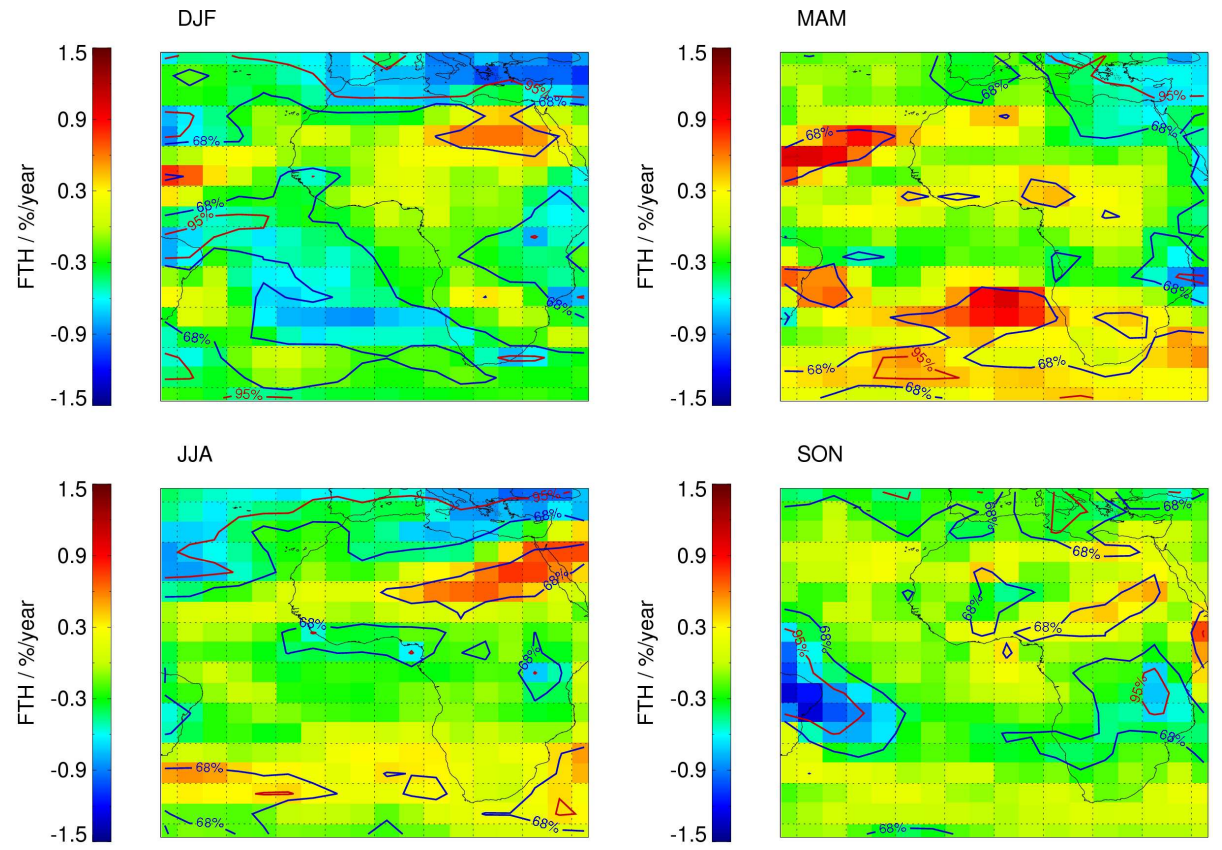

Figure 10. Same as Fig. 4 but for the linear trend in relative FTH. The blue and red contour lines show coverage probabilities of 68 and $95 \%$, respectively. Areas where only a small number of observations are valid are shown in grey.
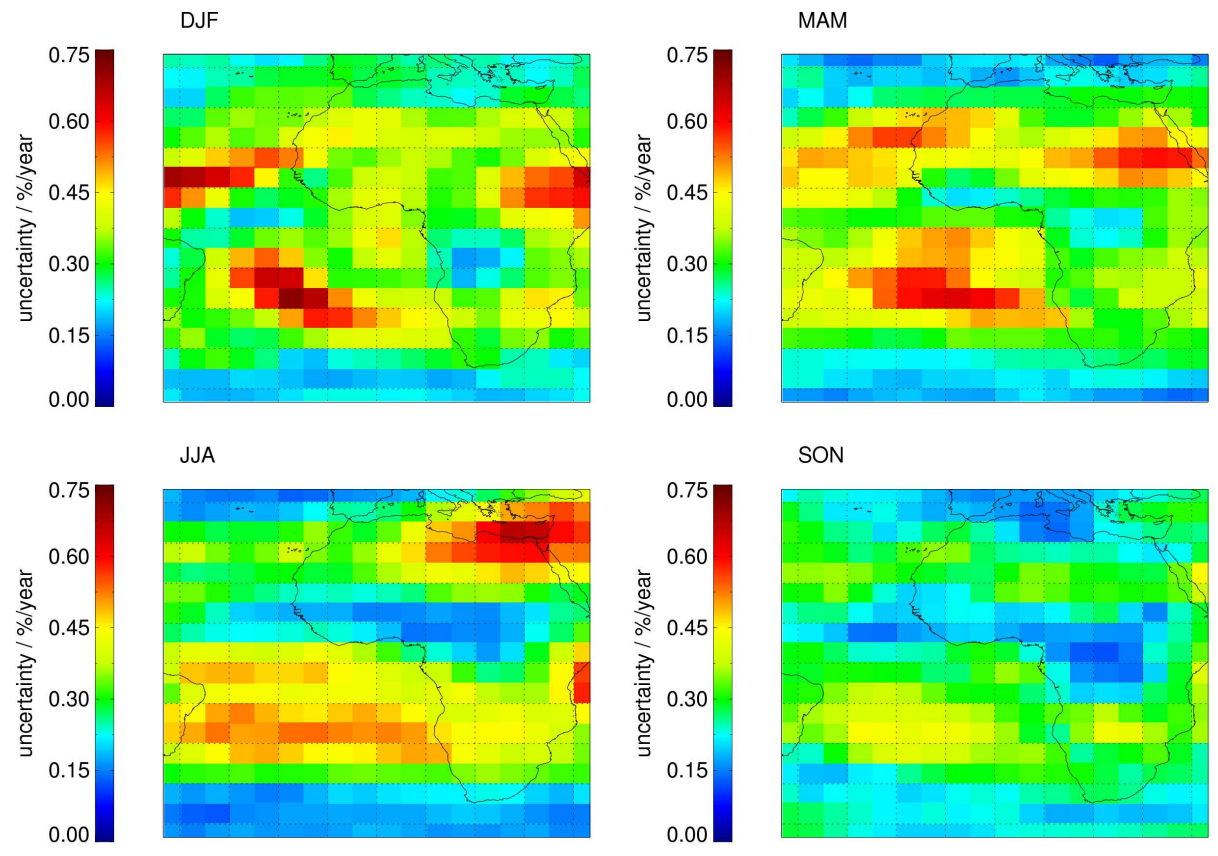

$$
\text { SON }
$$

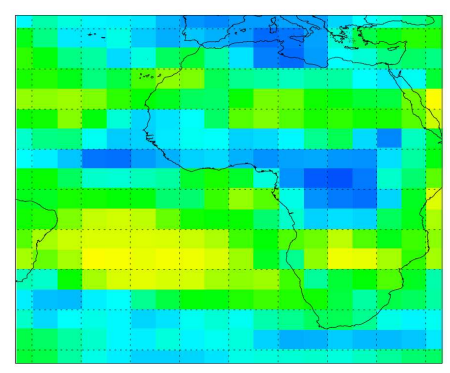

Figure 11. Same as Fig. 10 but for the uncertainty of the linear trend in relative FTH.

check whether trends in dry areas, in particular for FTHp10, are reproduced in reconstructions of tropospheric RH from back-trajectory models, in order to check whether such an increase could be related to a change in the large-scale dynamics of the last saturation statistics. In this context, the dipole structures of FTH and FTHp10 trends over north- eastern Africa in JJA and DJF are noteworthy. The associated feature in the estimated uncertainty coincides with a similar feature in interannual variability. The back-trajectory analysis should be extended with an analysis of the position and extent of the dry areas, specifically over northeastern Africa. 

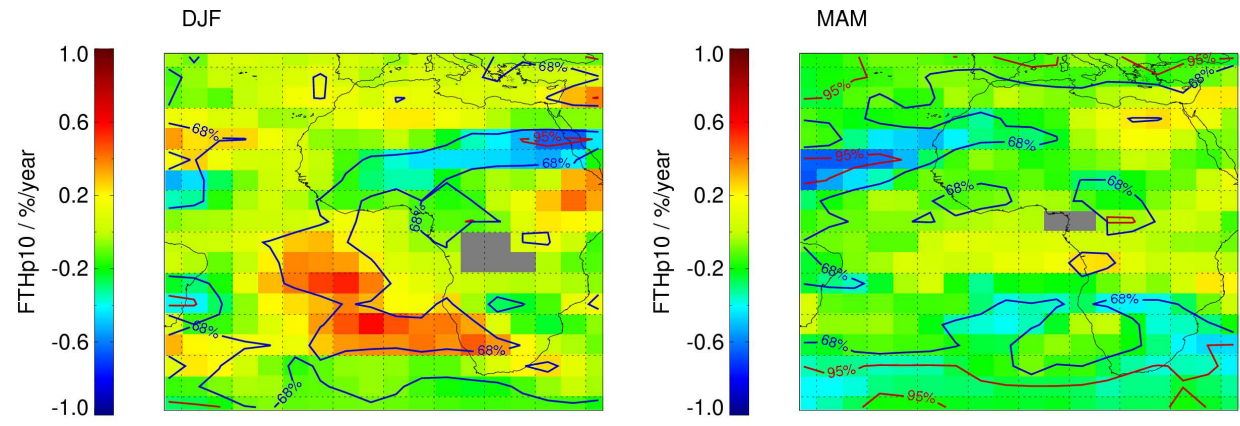

JJA
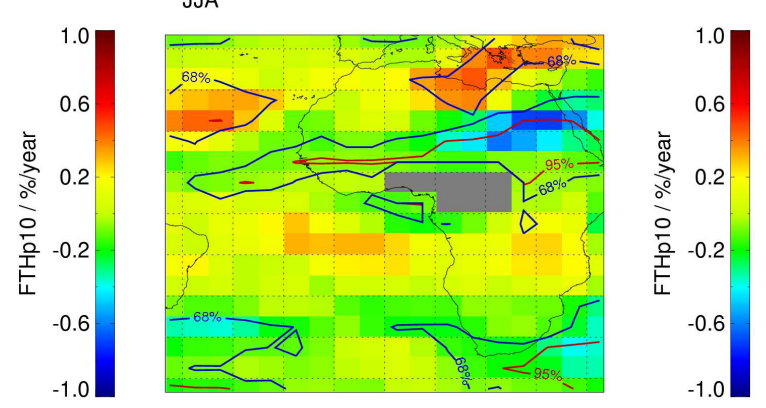

SON

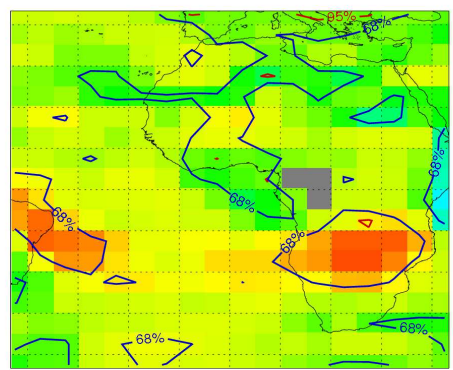

Figure 12. Same as Fig. 10 but for FTHp10.
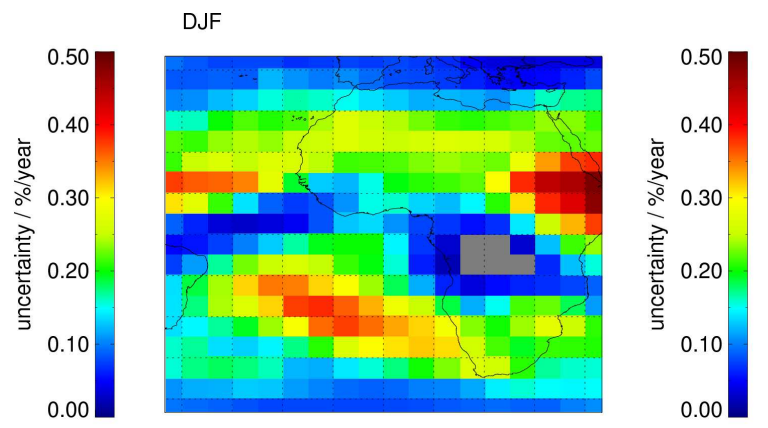

MAM
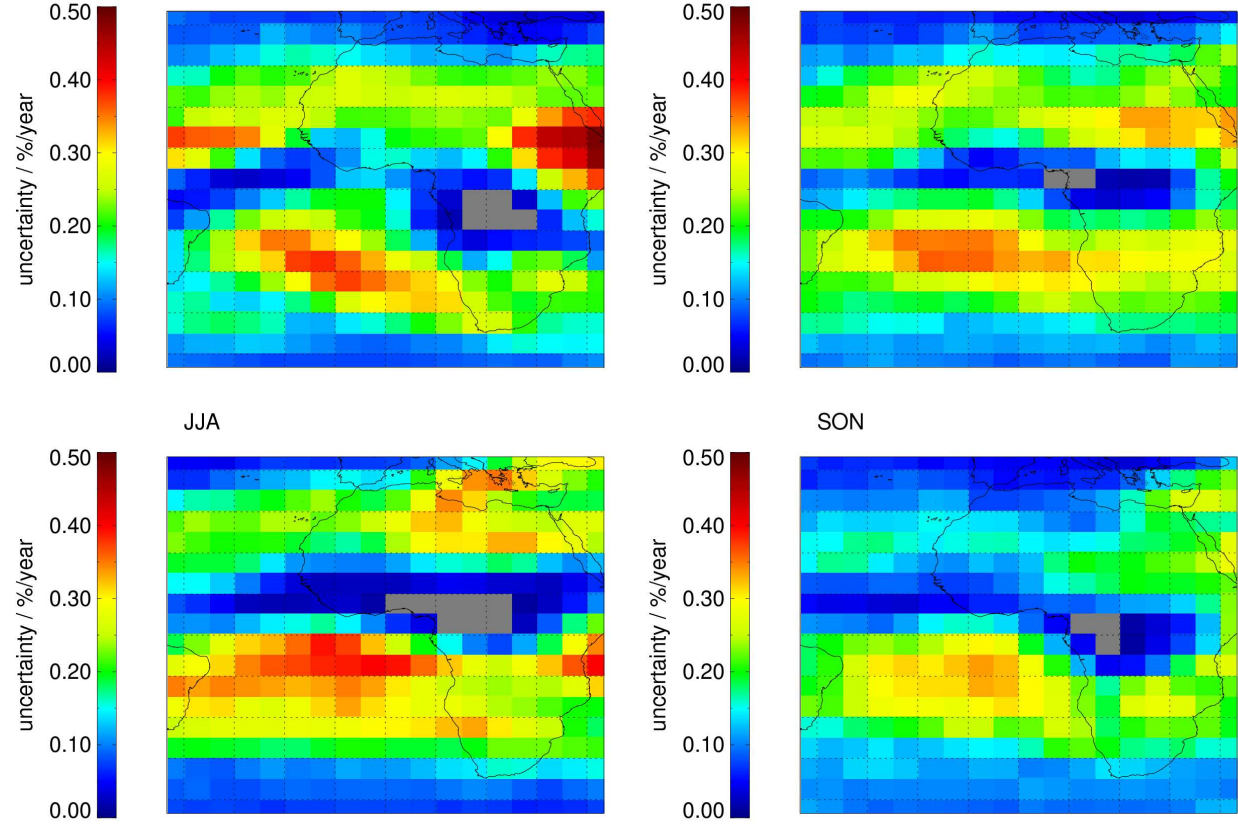

SON

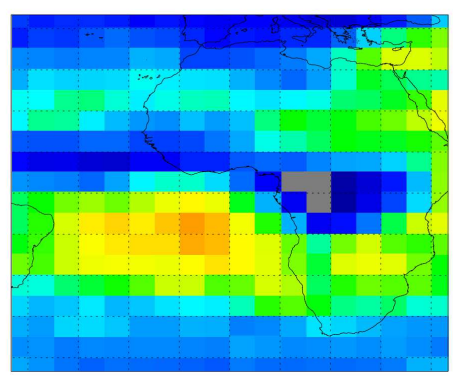

Figure 13. Same as Fig. 11 but for the uncertainty of the linear trend in FTHp10.

\section{Conclusions}

Meteosat-2-5 and Meteosat-7-9 observations at $6.3 \mu \mathrm{m}$ are used to retrieve information on humidity in the free troposphere. The inversion from BT to FTH is reliable in the clearsky case and in the presence of low-level clouds. Temper- ature data from ERA-Interim are used to slightly improve the performance of the statistical retrieval scheme. Thanks to a successful cooperation between a research institute and an operational service, the FTH data record was extended into the SEVIRI era. The FTH data record is now available, free of charge, from the European Organization for 
the Exploitation of Meteorological Satellites (EUMETSAT) Satellite Application Facility on Climate Monitoring (CM SAF) at https://www.cmsaf.eu/wui and is referenced under doi:10.5676/EUM_SAF_CM/FTH_METEOSAT/V001. The FTH data record is available within $\pm 45^{\circ} \mathrm{N} / \mathrm{S}$ and $\pm 45^{\circ} \mathrm{E} / \mathrm{W}$ with a spatial resolution of $0.625^{\circ} \times 0.625^{\circ}$, and it covers the period 1983-2009 with a temporal resolution of $3 \mathrm{~h}$. Monthly averages are also available.

Based on the comparison against FTH derived from the ARSA archive by using the RH Jacobians for the integration of the RH profiles, the average relative bias of the FTH product is $-3.2 \%$ and its relative RMSD is $16.8 \%$. The relative RMSD is in agreement with the estimated uncertainty. The decadal stability is $0.5 \pm 0.45 \%$. The relatively large uncertainty estimate covers the GCOS requirement on humidity in the free troposphere of $0.3 \%$ per decade. Due to the increase in bias between summer 1988 and summer 1990, and due to a maximum bias in January 1996, with generally spurious biases in 1996, and even though significant efforts have been dedicated to the homogenization of the Meteosat time series, the quality of the FTH data record will benefit from an FCDR of the full Meteosat time series, including the recovery of Meteosat- 6 data in order to close data gaps in the time series.

The interannual relative standard deviation of FTH and FTHp10, the differences between FTHp10 averaged over the 2000s and over the 1990s, and linear trends using seasonal averages of FTH and FTHp10 have been analyzed. Maxima in interannual standard deviations generally coincide with minima in FTH and maxima in FTHp10. Maxima in absolute estimates of the trends in seasonal FTH and FTHp10 are associated with maxima in standard deviation. As a result, the estimated trends are hardly significant. In the ITCZ region, where the results could be corrupted by the cloud-clearing method, the trends and their uncertainties must be interpreted with caution. However, the maxima in the trend estimate of FTHp10 coincide with maximum absolute differences in FTHp10 averaged over the 2000s and over the 1990s. The linear analysis performed in the dry free-tropospheric subtropical regions leads to results that are not significant but are consistent with theoretical considerations in both the sign and the small magnitude of the change over the last $\sim 25$ years. The combination of trend estimates, coverage probability and estimated uncertainty provides valuable information to further analyze changes in the climate system. The analysis of the dry end of the FTH distribution is very relevant, not only because of its impact on OLR but also because of the observed indication of small changes in value, area and associated large variability.
This analysis will benefit from the availability of a Meteosat FCDR and a gap-free input data record. It will also benefit from the extension of the temporal coverage to the most recent times in order to promote a robust view on the decadal changes estimated here using linear trends computations. Within the WMO's SCOPE-CM project, EUMETSAT leads the "Inter-calibration of imager observations from time-series of geostationary satellites" project. Among others things, the aim of this project is the development and the provision of a Meteosat FCDR. This FCDR will be used to improve the quality of the Meteosat-based FTH data record.

Initial comparisons to other available FTH records (e.g., based on HIRS and AMSU-B observations) have already been carried out by CM SAF (http://www.cmsaf.eu/docs) and by G-VAP (http://www.gewex-vap.org). The work presented here is part of the analysis of long-term temporal changes within G-VAP. The extension of this analysis to other FTH data records and the inter-comparison is in progress and is being performed by an international team associated with G-VAP.

Acknowledgements. This work was carried out within the framework of a memorandum of understanding between CNRS and EUMETSAT's CM SAF. The authors acknowledge the financial support by CNRS and by the EUMETSAT member states. The authors are grateful to the ARA/ABC(t)/LMD group, NASA, the NOAA Climate Data Center and ECMWF for producing and making available ARSA and ISCCP-DX data records as well the El Niño 3.4 and QBO indices and ERA-Interim data, respectively. J. Schulz from EUMETSAT is acknowledged for initiating the cooperation that led to the presented results. Finally, we acknowledge the two anonymous reviewers for their comments.

Edited by: R. Krejci 


\section{Appendix A: Statistical quantities}

In this Appendix, frequently used statistical quantities are defined:

- The relative systematic difference (or relative bias) between two estimations $x_{i}$ and $y_{i}$ of the same variable is computed as

relative bias $=\frac{1}{N} \sum_{i=1}^{N} \frac{\left(y_{i}-x_{i}\right)}{x_{i}} \times 100$.

The relative RMSD is defined as follows:

relative $\mathrm{RMSD}=$

$$
\sqrt{\frac{1}{(N-1)} \sum_{i=1}^{N}\left(\frac{\left(\left(y_{i}-\text { bias }\right)-x_{i}\right)}{x_{i}} \times 100\right)^{2}} .
$$

In Eqs. (A1) and (A2) the sum is computed for all valid pairs within a given month, noted $N$. Absolute bias and RMSD are computed by omitting the factor $100 / x_{i}$ in Eqs. (A1) and (A2). The term "absolute" is usually omitted.
- Decadal stability is computed by applying linear regression analysis to the results from Eq. (A1). The slope of the regression is the temporal change of the relative bias per month in percent per month. When multiplying by 120 , the decadal stability is in percent per decade.

- The Pearson's correlation coefficient $R$ between the variables $x$ and $y$, each having $N$ elements, is defined as follows:

$R=$

$$
\frac{N \sum_{i=1}^{N} x_{i} y_{i}-\sum_{i=1}^{N} x_{i} \sum_{i=1}^{N} y_{i}}{\sqrt{N \sum_{i=1}^{N} x_{i}^{2}-\left(\sum_{i=1}^{N} x_{i}\right)^{2}} \times \sqrt{N \sum_{i=1}^{N} y_{i}^{2}-\left(\sum_{i=1}^{N} y_{i}\right)^{2}}} .
$$

Note that the $N$ can differ from the $N$ in Eqs. (A1) and (A2). 


\section{Appendix B: Abbreviations}

Table B1. List of abbreviations.

\begin{tabular}{|c|c|}
\hline Abbreviation & Word/phrase \\
\hline AMSU-B & Advanced Microwave Sounding Unit-B \\
\hline ARSA & Analyzed RadioSoundings Archive \\
\hline BT & Brightness temperature \\
\hline CM SAF & Satellite Application Facility on Climate Monitoring \\
\hline CSR & Clear-sky radiance \\
\hline DJF & December/January/February \\
\hline ECMWF & European Centre for Medium-Range Forecasts \\
\hline ERA-Interim, ERA-40 & ECMWF Reanalysis \\
\hline EUMETSAT & European Organisation for the Exploitation of Meteorological Satellites \\
\hline FCDR & Fundamental Climate Data Record \\
\hline FTH & Free-tropospheric humidity \\
\hline FTHp10 & Frequency of occurrence of $\mathrm{FTH}<10 \% \mathrm{RH}$ \\
\hline GCOS & Global Climate Observing System \\
\hline GEWEX & Global Energy and Water cycle EXperiment \\
\hline G-VAP & GEWEX water VAPor assessment \\
\hline HIRS & High-resolution Infrared Radiation Sounder \\
\hline ISCCP-DX & International Satellite Cloud Climatology Project, DX type \\
\hline ITCZ & Intertropical Convergence Zone \\
\hline JJA & June-July-August \\
\hline LMD & Laboratoire de Météorologie Dynamique \\
\hline MAM & March-April-May \\
\hline Meteosat & Meteorological Satellite \\
\hline MVIRI & Meteosat Visible Infra-Red Imager \\
\hline NetCDF & Network Common Data Format \\
\hline NOAA & National Oceanic and Atmospheric Administration \\
\hline OLR & Outgoing longwave radiation \\
\hline QBO & Quasi-biennial oscillation \\
\hline RH & Relative humidity \\
\hline RMSD & Root-mean-square difference \\
\hline RTTOV & Radiative Transfer for the TIROS Operational Vertical Sounder \\
\hline SAF & Satellite Application Facility \\
\hline SCOPE-CM & Sustained, Coordinated Processing of Environmental Satellite Data for Climate Monitoring \\
\hline SEVIRI & Spinning Enhanced Visible and InfraRed Imager \\
\hline SON & September-October-November \\
\hline WMO & World Meteorological Organization \\
\hline
\end{tabular}




\section{References}

Bréon, F.-M., Jackson, D. L., and Bates, J. J.: Calibration of the Meteosat water vapor channel using collocated NOAA/HIRS 12 measurements, J. Geophys. Res., 105, 11925-11933, 2000.

Brogniez, H.: African Free Tropospheric Humidity: Elaboration of a METEOSAT archive, Climatic analysis and Evaluation of models, $\mathrm{PhD}$ thesis, University of Pierre and Marie Curie, Paris, France, 2004.

Brogniez, H., Roca, R., and Picon, L.: Interannual and Intraseasonal variabilities of the Free Tropospheric Humidity using METEOSAT water vapour channel over the tropics, Proc. of the Eumetsat Meteorological Satellite Conference, Prague, Czech Republic, 31-4, June 2004.

Brogniez, H., Roca, R., and Picon, L.: Evaluation of the distribution of subtropical Free Tropospheric Humidity in AMIP-2 simulations using Meteosat Water Vapor channel data, Geophys. Res. Letters, 32, L19708, doi:10.1029/2005GL024341, 2005.

Brogniez, H., Roca, R., and Picon, L.: A clear sky radiances archive from Meteosat "water vapor" observations, J. Geophys. Res., 111, D21109, doi:10.1029/2006JD007238, 2006.

Brogniez, H., Roca, R., and Picon, L.: A study of the free tropospheric humidity interannual variability using Meteosat data and an advection-condensation transport model, J. Climate, 22, 6773-6787, 2009.

Brogniez, H., Clain, G., and Roca, R.: Upper Tropospheric Humidity from SAPHIR/Megha-Tropiques: algorithm overview and validation against tropical soundings, J. Appl. Meteorol. Climatol., submitted, 2014.

Brunel, P. and Turner, S.: On the use of Planck-weighted transmittances in RTTOV presented at the 13th International TOVS Study Conference, Ste Adele, Canada, 29 October-4 November 2003.

Buehler, S. A. and John, V. O.: A simple method to relate microwave radiances to upper tropospheric humidity, J. Geophys. Res., 110, D02110, doi:10.1029/2004JD005111, 2005.

Buehler, S. A., Kuvatov, M., John, V. O., Milz, M., Soden, B. J., Jackson, D. L., and Notholt, J.: An upper tropospheric humidity data set from operational satellite microwave data, J. Geophys. Res., 113, D14110, doi:10.1029/2007JD009314, 2008.

Chambon, P., Jobard, I., Roca, R., and Viltard, N.: An investigation of the error budget of tropical rainfall accumulation derived from merged passive microwave and infrared satellite measurements, Q. J. Roy. Meteor. Soc., 139, 879-893, doi:10.1002/qj.1907, 2012.

Chen, Y., Han, Y., Van Delst, P., and Weng, F.: On water vapor Jacobian in fast radiative transfer model, J. Geophys. Res., 115, D12303, doi:10.1029/2009JD013379, 2010.

Clough, S., Kneizys, F., and Davies, R.: Line shape and the water vapor continuum, Atmos. Res., 23, 229-241, 1989.

Dee, D. P., Uppala, S. M., Simmons, A. J., Berrisford, P., Poli, P., Kobayashi, S., Andrae, U., Balmaseda, M. A., Balsamoa, G., Bauer, P., Bechtold, P., Beljaars, A. C. M., van de Berg, L., Bidlot, J., Bormann, N., Delsol, C., Dragani, R., Fuentes, M., Geer, A. J., Haimberger, L., Healy, S. B., Hersbach, H., Holm, E. V., Isaksen, L., Kallberg, P., Köhler, M., Matricardi, M., McNally, A. P., Monge-Sanz, B. M., Morcrette, J.-J., Park, B.-K., Peubey, C., de Rosnay, P., Tavolato, C., Thepaut, J.-N., and Vitart, F.: The ERA-Interim reanalysis: configuration and performance of the data assimilation system, Q. J. Roy. Meteor. Soc., 137, 553-597, 2011.
Durre, I., Vose, R. S., and Wuertz, D. B.: Overview of the Integrated Global Radiosonde Archive, J. Climate, 19, 53-68, 2006.

Edwards, D.: GENLN2: a general line-by-line atmospheric transmittance and radiance model, Tech. Rep., NCAR/TN-367, 1992.

Eyre, J.: On systematic errors in satellite sounding products and their climatological mean values, Q. J. Roy. Meteor. Soc., 113, 279-292, 1987.

Held, I. M. and Soden, B. S.: Robust Responses of the Hydrological Cycle to Global Warming, J. Climate, 19, 5686-5699, doi:10.1175/JCLI3990.1, 2006.

Hurley, J. V. and Galewsky, J.: A last-saturation diagnosis of subtropical water vapor response to global warming, Geophys. Res. Lett., 37, L06702, doi:10.1029/2009GL042316, 2010.

GCOS-154: Systematic Observation Requirements for Satellitebased Products for Climate. Supplemental details to the satellitebased component of the Implementation Plan for the Global Observing System for Climate in Support of the UNFCCC (Update), December 2011.

Jackson, D. and Bates, J.: Upper tropospheric humidity algorithm assessment, J. Geophys. Res., 106, 32259-32270, 2001.

John, V. O., Holl, G., Allan, R. P., Buehler, S. A., Parker, D. E., and Soden, B. J.: Clear-sky biases in satellite infrared estimates of upper tropospheric humidity and its trends, J. Geophys. Res., 116, D14108, doi:10.1029/2010JD015355, 2011.

John, V. O., Holl, G., Atkinson, N., and Buehler, S. A.: Monitoring scan asymmetry of microwave humidity sounding channels using simultaneous all angle collocations (SAACs), J. Geophys. Res.Atmos., 118, 1536-1545, doi:10.1002/jgrd.50154, 2013.

Köpken, C.: Monitoring of Meteosat WV radiances and solar stray light effects, EUMETSAT/ECMWF Fellowship Report No. 10, 2001.

Matricardi, M., Chevallier, F., Kelly, G., and Thépaut, J.-N.: An improved general fast radiative transfer model for the assimilation of radiance observations, Q. J. Roy. Meteor. Soc., 130, 153-173, 2004.

Moradi, I., Buehler, S. A., and John, V. O.: Comparing upper tropospheric Humidity from Microwave satellite instruments and IGRA radiosonde data, 11th Specialist Meeting on Microwave Radiometry and Remote Sensing of the Environment, MicroRad, IEEE Communications Society, New York, 146-151, doi:10.1109/MICRORAD.2010.5559573, 2010.

Picon, L., Roca, R., Serrar, S., and Desbois, M.: A new METEOSAT "water vapor" archive for climate studies, J. Geophys. Res., 108, 4301, doi:10.1029/2002JD002640, 2003.

Pierrehumbert, R. T., Brogniez, H., and Roca, R.: On the relative humidity of the atmosphere. The Global Circulation of the Atmosphere, edited by: Schneider, T. and Sobel, A. H., Princeton Univ. Press, 143-185, 2007.

Roca R., Brogniez, H., Picon, L., and Desbois, M.: Free Tropospheric humidity observations from Meteosat water vapour channel data. Preprints, 17th Conf. on Hydrology, Long Beach, CA, Amer. Meteor. Soc., CD-ROM, J3.7, 2003.

Roca, R., Brogniez, H., Gif, N., and Picon, L.: Development of a consistent climatology of free tropospheric humidity employing observations from Meteosat satellites. EUMETSAT CM SAF Scientific and Technical Report, 23 October 2009.

Roca, R., Chambon, P., Jobard, I., Kirstetter, P. E., and Gosset, M.: Comparing satellite and surface rainfall products over West Africa at meteorologically relevant scales during the AMMA 
campaign using error estimates, J. Appl. Meteorol. Clim., 49, 715-731, 2010.

Roca, R., Guzman, R., Lemond, J., Meijers, J., Picon, L., and Brogniez, H.: Tropical and extra-tropical influences on the distribution of free tropospheric humidity over the intertropical belt, Surv. Geophys., 33, 565-583, doi:10.1007/s10712-011-9169-4, 2011.

Roca, R., Meijer-Fofana, J., Picon, L., and Brogniez, H.: Climatology of free tropospheric humidity: Extension to SEVIRI, error analysis and trend assessment, EUMETSAT CM SAF Scientific and Technical Report, June 2012.

Rossow, W. B. and Schiffer, R. A.: Advances in Understanding Clouds from ISCCP, B. Am. Meteorol. Soc., 80, 2261-2288, 1999.

Rothman, L. S., Barbe, A., Benner, D. C., Brown, L. R., CamyPeyret, C., Carleer, M. R., Chance, K., Clerbaux, C., Dana, V., Devi, V. M., Fayt, A., Flaud, J.-M., Gamache, R. R., Goldman, A., Jacquemart, D., Jucks, K. W., Lafferty, W. J., Mandin, J.-Y., Massie, S. T., Nemtchinov, V., Newnham, D. A., Perrin, A., Rinsland, C. P., Schroeder, J., Smith, K. M., Smith, M. A. H., Tang, K., Toth, R. A., Vander Auwera, J., Varanasi, P., and Yoshino, K.: The HITRAN molecular spectroscopic database: edition of 2000 including updates through 2001, J. Quant. Spectrosc. Ra., 82, 5-44, 2003.

Santer, B. D., Mears, C., Doutriaux, C., Caldwell, P., Gleckler, P. J., Wigley, T. M. L., Solomon, S., Gillett, N. P., Ivanova, D., Karl, T. R., Lanzante, J. R., Meehl, G. A., Stott, P. A., Taylor, K. E., Thorne, P. W., Wehner, M. F., and Wentz, F. J.: Separating signal and noise in atmospheric temperature changes: The importance of timescale, J. Geophys. Res., 116, D22105, doi:10.1029/2011JD016263, 2011.

Schmetz, J. and Turpeinen, O.: Estimation of the upper tropospheric relative humidity field from METEOSAT water vapor image data, J. Appl. Meteor., 27, 889-899, 1988.

Schmetz, J., Geijo, C., Menzel, W. P., Strabala, K., van de Berg, L., Holmlund, K., and Tjemkes, S.: Satellite observations of upper tropospheric relative humidity, clouds and wind field divergence, Beitr. Phys. Atmos., 68, 345-357, 1995.

Schmetz, J., Pili, P., Tjemkes, S., Just, D., Kerkmann, J., Rota, S., and Ratier, A.: An introduction to Meteosat Second Generation (MSG), B. Am. Meteorol. Soc., 83, 977-992, 2002.

Sherwood, S. C., Roca, R., Weckwerth, T., and Andronova, N.: Tropospheric water vapor, convection and climate, Rev. Geophys., 48, RG2001, doi:10.1029/2009RG000301, 2010a.

Sherwood, S. C., Ingram, W., Tsushima, Y., Satoh, M., Roberts, M., Vidale, P. L., and O'Gorman, P. A.: Relative humidity changes in a warmer climate, J. Geophys. Res., 115, D09104, doi:10.1029/2009JD012585, 2010b.

Shi, L. and Bates, J. J.: Three decades of intersatellitecalibrated High-Resolution Infrared Radiation Sounder upper tropospheric water vapor, J. Geophys. Res., 116, D04108, doi:10.1029/2010JD014847, 2011.

Shi, L., Schreck III, C. J., and John, V. O.: HIRS channel 12 brightness temperature dataset and its correlations with major climate indices, Atmos. Chem. Phys., 13, 6907-6920, doi:10.5194/acp13-6907-2013, 2013.
Soden, B. and Bretherton, F.: Upper tropospheric relative humidity from the GOES 6.7 im channel: method and climatology for July 1987, J. Geophys. Res., 98, 16669-16688, 1993.

Soden, B. J. and Bretherton, F. P.: Interpretation of TOVS water vapor radiances in terms of layer average relative humidities: Method and climatology for the upper, middle, and lower troposphere, J. Geophys. Res., 101, 9333-9343, doi:10.1029/96JD00280, 1996.

Soden, B., Tjemkes, S., Schmetz, J., Saunders, R., Bates, J., Ellingson, B., Engelen, R., Garand, L., Jackson, D., Jedlovec, G., Kleespies, T., Randel, D., Rayer, P., Salathe, E., Schwarzkopf, D., Scott, N., Sohn, B., de Souza-Machado, S., Strow, L., Tobin, D., Turner, D., van Delst, P., and Wehr, T.: An intercomparison of radiation codes for retrieving upper-tropospheric humidity in the $6.3 \mathrm{im}$ band: a report from the first GvaP workshop, B. Am. Meteorol. Soc., 81, 797-808, 2000.

Soden, B. J., Wetherald, R. T., Stenchikov, G. L., and Robock, A.: Global cooling after the eruption of Mount Pinatubo: a test of climate feedback by water vapor, Science, 296, 727-730, 2002.

Sohn, B. J. and Schmetz. J.: Water vapor-induced OLR variations associated with high cloud changes over the tropics: a study from meteosat-5 observations, J. Climate, 17, 1987-1996, 2004.

Spencer, R. and Braswell, W. D.: How dry is the tropical free troposphere? Implications for global warming theory, B. Am Meteorol. Soc., 78, 1097-1106, 1997.

Stephens, G., Jackson, D., and Wittmeyer, I.: Global observations of upper tropospheric water vapor derived from TOVS radiance data, J. Climate, 9, 305-326, 1996.

Theil, H.: A rank-invariant method of linear and polynomial regression analysis I, II, III, Nederl. Akad. Wetensch. Proc., 53, 386392, 521-525, 1397-1412, 1950.

Udelhofen, P. M. and Hartmann, D. L.: Influence of tropical cloud systems on the relative humidity in the upper troposphere, J. Geophys. Res., 100, 7423-7440, 1995.

Uppala, S. M., Kallberg, P. W., Simmons, A. J., Andrae, U., Da Costa Bechtold, V., Fiorino, M., Gibson, J. K., Haseler, J., Hernandez, A., Kelly, G. A., Li, X., Onogi, K., Saarinen, S., Sokka, N., Allan, R. P., Andersson, E., Arpe, K., Balmaseda, M. A., Beljaars, A. C. M., Vande Berg, L., Bidlot, J., Bormann, N., Caires, S., Chevallier, F., Dethof, A., Dragosavac, M., Fisher, M., Fuentes, M., Hagemann, S., Holm, E., Hoskins, B. J., Isaksen, L., Janssen, P. A. E. M., Jenne, R., McNally, A. P., Mahfouf, J.-F., Morcrette, J.-J., Rayner, N. A., Saunders, R.W., Simon, P., Sterl, A., Trenberth, K. E., Untch, A., Vasiljevic, D., Viterbo, P., and Woollen, J.: The ERA-40 re-analysis, Q. J. Roy. Meteor. Soc., 131, 2961-3012, 2005.

van de Berg, L. C. J., Schmetz, J., and Whitlock, J.: On the Calibration of the Meteosat Water Vapour Channel, J. Geophys. Res., 100, 21069-21076, 1995.

Wilcox, R. R.: Theil-Sen estimator, Fundamentals of Modern Statistical Methods: Substantially Improving Power and Accuracy, Springer-Verlag, New York, 207-210, 2001.

Wilks, D. S.: Statistical Methods in the Atmospheric Sciences, Academic Press, Oxford, 3rd revised Edn., 2011. 